\title{
Directional Sharp-Point Failure Mechanism of Rocks Surrounding Underground Circular Cavities Subjected to Large-Scale Failure
}

\author{
Xiao-fei Guo $\mathbb{D}^{1},{ }^{1}$ Zhiqiang Zhao $\mathbb{D}^{1},{ }^{1}$ Xu Gao, ${ }^{1}$ Zhen-kai Ma, ${ }^{2}$ and Nian-jie $\mathrm{Ma}^{1}$ \\ ${ }^{1}$ Faculty of Resource and Safety Engineering, China University of Mining and Technology (Beijing), Beijing 100083, China \\ ${ }^{2}$ College of Mining Engineering, Liaoning Technical University, Fuxin, Liaoning 123000, China \\ Correspondence should be addressed to Zhiqiang Zhao; caikuangren@126.com
}

Received 15 October 2018; Revised 11 January 2019; Accepted 17 January 2019; Published 27 February 2019

Academic Editor: Gregory Chagnon

Copyright (C) 2019 Xiao-fei Guo et al. This is an open access article distributed under the Creative Commons Attribution License, which permits unrestricted use, distribution, and reproduction in any medium, provided the original work is properly cited.

Large-scale expansion of failure areas in rocks surrounding underground cavities causes severe destruction of the underground space and may trigger serious disasters. To study the large-scale failure mechanism and expansion laws of rocks surrounding underground cavities, we performed a theoretical study of the distribution characteristics of the stress field around a circular cavity and determined the directional sharp-point failure mechanism by analysing the stress destructive power using the three elements of the Mohr circle. Results showed that, along the circumferential direction, the stress destructive power increases first and then decreases, showing a sharp-angular distribution. Rock with any properties will suffer priority damage at the stress sharp point. The direction criterion of the stress sharp points was proposed, and the direction of these points showed a convergent behaviour in the radial direction of the cavity, tending to be stable at $40^{\circ}-50^{\circ}$ beyond five times the cavity radius. In addition, the results were verified by FLAC ${ }^{3 \mathrm{D}}$ numerical simulation. The theoretical analysis for the ideal circular cavity may provide references to study the damage laws of rocks surrounding other irregular-shaped space, as well as providing a theoretical basis for the prevention and control of underground engineering disasters.

\section{Introduction}

Groundwater erosion, deep magmatic activities, karst processes, and other crustal geological activities lead to a large number of large-scale caverns in the underground rock strata [1-4]. In the extraction of underground resources, a large number of engineering holes have been formed artificially, such as roadways, gas drainage boreholes, and oil and natural gas drillings [5-8]. As a natural heterogeneous geological material, rock contains many microscopic cavities, cracks, joints, and other defects, and the cavity is one of the basic forms of micro-defects in rocks $[9,10]$. Studying the damage laws of rock surrounding a cavity is important for understanding the occurrence mechanism of geological disaster, maintaining the stability of underground engineering space, and preventing underground engineering disasters.

Two previous studies on the damage laws of rocks surrounding have been conducted. The first one focused on the mechanical properties and the crack development process of pre-cavity rock specimen, and the second one focused on the failure laws and the stability of the rock surrounding an excavation space in an underground engineering field.

Research on the mechanical response of pre-cavity rock specimens mainly focused on the initiation and development process of the crack around a circular cavity [11-15]. With the development of experimental techniques, many researchers have used microscopy, scanning electron microscopy, acoustic emission, high-speed photography, and other experimental methods, combined with numerical simulation, to study the crack propagation laws [16-19]. The results show that the existence of void defects has a great impact on the mechanical properties and fracture of rocks. In particular, most of the stress loading in previous research was under a uniaxial loading condition [20-22]. Although triaxial loading conditions have been used in some laboratory and numerical simulation tests $[23,24]$, owing to the lack of corresponding theoretical 


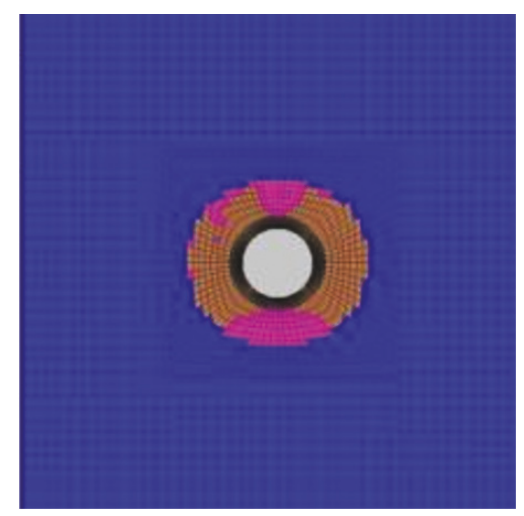

Elastic zone Plastic zone

(a) Circular shape, $\lambda=1$

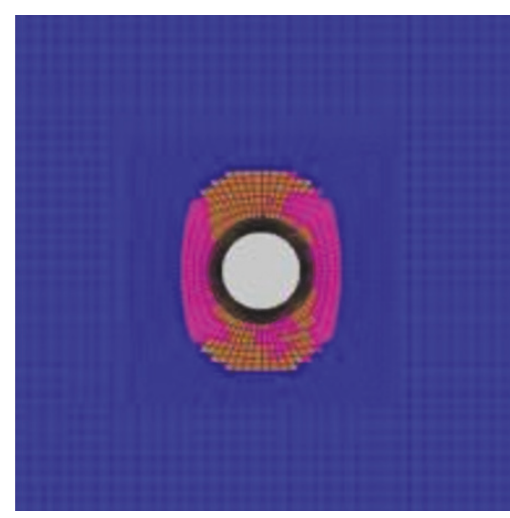

Elastic zone Plastic zone

(b) Elliptical shape, $\lambda=1.3$

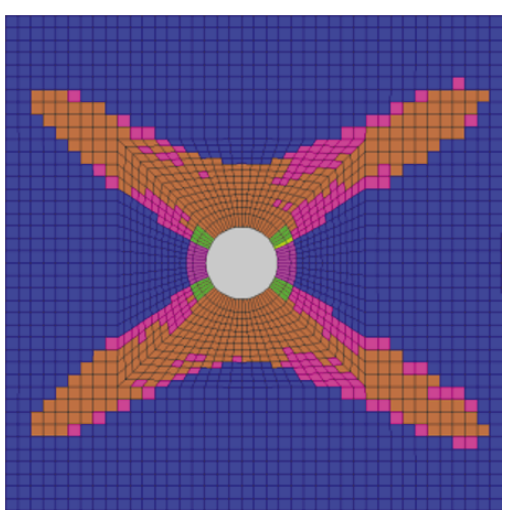

Elastic zone

Plastic zone

(c) Butterfly shape, $\lambda=3$

FIgURE 1: Circular-shaped roadway plastic zones under different stress conditions [25].

guidance, the loading methods are heavily restricted. The test conditions determined that the test block should have a small scale, and the test results are affected by other interference factors. The results of the large-scale failure around a cavity are difficult to perform in the laboratory.

In an infinite underground space, roadways can be regarded as cavities in the underground rock stratum. So far, much field experience and many useful research results on the damage laws of the rock surrounding a roadway have been obtained. According to the engineering geological conditions and the disaster characteristics of the rock surrounding a roadway, many scholars payed more attention to the destruction laws in the area of the roof, floor, and two gangs [2629]. Under general geological conditions, the depth of a roadway is relatively shallow and the confining pressure is small. In this way, the damage range of the rock surrounding is not large. The research scope for the failure laws of the rock surrounding a roadway is basically limited to within five times the roadway radius. However, for serious disasters, such as roadway large deformation, rock-burst, coal and gas outburst, and mine shock, the rock surrounding a roadway is under complicated geological conditions, and its damage scope is very large, perhaps reaching more than 10 or even several dozen times the roadway radius [30-32]. Ma et al. pointed out that the failure zone of the rock surrounding a roadway would expand widely in an environment with soft rock and high partial stress, and they obtained the 'butterflyshaped' distribution of a large-scale destruction area through numerical simulation [25, 33-37], as illustrated in Figure 1 (vertical stress: $P_{Z}=20 \mathrm{MPa}$; roadway radius: $r=2.5 \mathrm{~m}$; rock cohesion: $C=3 \mathrm{MPa}$; rock internal friction angle: $\varphi=25^{\circ}$ ). Figures 1(a) and 1(b) show the shapes of the roadway plastic zone when the surrounding rock was slightly damaged, and Figure 1(c) shows a butterfly-shaped plastic zone when the rock surrounding is extensively damaged. When the damage area was small, it was almost uniformly distributed around the roadway. When the damage area scope was extended to a certain range, it was in a sharp-angular distribution with an obvious angle and direction. It can be seen that the failure propagation laws of the surrounding rock were completely different when the failure scope around a cavity was different. The phenomena of sharp-point failure around a roadway, such as the butterfly-shaped plastic zone, have been discussed in existing literature studies. However, the findings were mostly the results of numerical simulation calculation. The formation mechanism and propagation laws of the sharppoint failure remain unclear, and research on the sharp-point failure propagation direction is insufficient. Therefore, it is necessary to study the mechanism and propagation rules of large-scale failure around a cavity.

In this work, the mechanisms and propagation laws of rock surrounding underground circular cavities subjected to large-scale failure were studied. The distribution laws of the stress field around a circular cavity were studied, and failure laws of the surrounding rock under different stress conditions were explored according to the Mohr-Coulomb strength criterion. The impact of the lateral pressure coefficient on the failure of the rock surrounding a circular cavity was studied, and the lateral pressure coefficient varied from 2 to 10 to uniaxial compression condition. To study the damaged region expansion laws, we varied the influence range of the circular cavity from 2 to 40 times the cavity radius. The relationship between the damaged region expansion direction and the stress field was studied, and the directional sharp-point failure mechanism was determined.

\section{Distribution Characteristics of the Circumferential Stress Field around a Circular Cavity}

The sharp angle failure of the rock surrounding a circular cavity is related to the distribution characteristics of the stress field. To understand the mechanism of sharp-point failure, we need to fully study the distribution characteristics of the stress field around a circular cavity. 


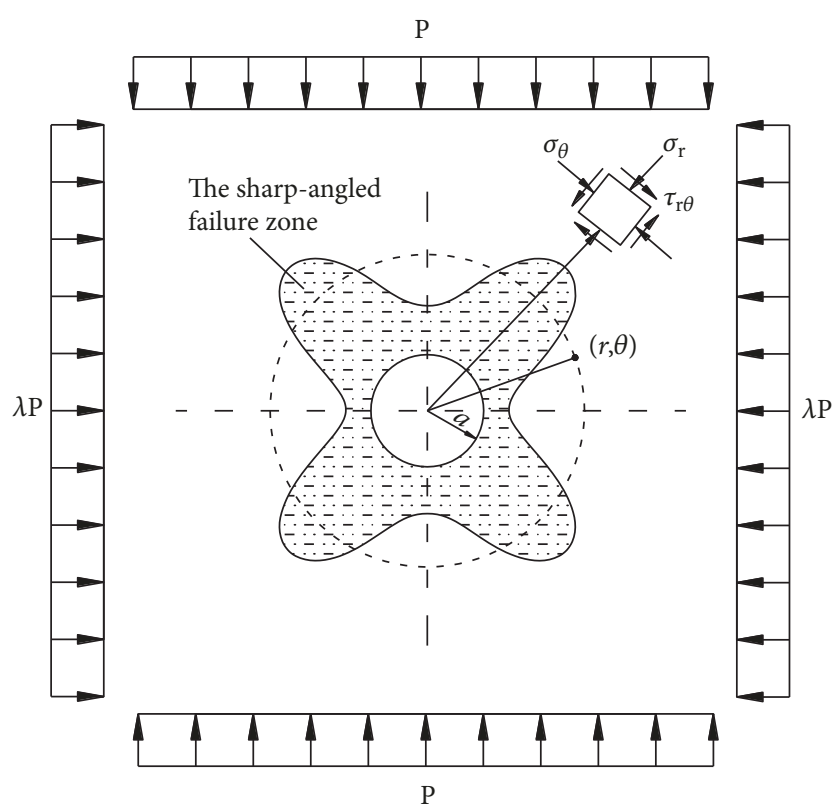

FIGURe 2: Plane strain stress model of the rock surrounding a circular cavity in a nonuniform stress field.

2.1. Mechanical Model. In reality, underground conditions are complex and changeable. To facilitate research and find rules more easily, we need to make the following assumptions: the length of the circular cavity is much larger than its diameter and is considered to be infinite; the horizontal and vertical stresses do not change along the length, and the surrounding rock is a homogeneous continuous medium without creep and viscous behaviour. Therefore, the plane strain method can be used and take any section as a research representative of the infinite cavity [38-40]. The plane strain model is proposed to simplify the space problems in mechanics. In the model, only the strain in the plane is considered, whereas the strain in the vertical direction is neglected. On the basis of the assumptions on the circular cavity and surrounding rock conditions, the axial strain of the circular cavity can be neglected. A plane strain model of the rock surrounding a circular cavity in a nonuniform stress field was developed and is shown in Figure 2.

In the figure, $a$ is the circular cavity radius, $r$ and $\theta$ are the polar coordinates of any point in the coordinate system, $P$ is the vertical stress, and the horizontal stress is obtained by the product of the lateral pressure coefficient $\lambda$ and the vertical stress $P$. According to the statistical results of the measured data $[41,42]$, in the actual underground stress field, the general horizontal stress was greater than the vertical stress. In many cases, the ratio of the horizontal stress to the vertical stress was more than 2, and the maximum could be even up to 30 . Under some special conditions, when the vertical stress is greater than the horizontal stress, the equivalence study method can be used by rotating the model by $90^{\circ}$. For convenience, the study considered only the condition in which the side pressure coefficient was greater than 1 , as shown in formula (1).

$$
\lambda>1
$$

According to previous results from elastic mechanics $[43,44]$, the solutions at any point around a circular cavity in a nonuniform stress field were obtained, as expressed in formula (2):

$$
\begin{aligned}
\sigma_{r} & =\frac{P}{2}\left[(1+\lambda)\left(1-\frac{a^{2}}{r^{2}}\right)\right. \\
& \left.+(\lambda-1)\left(1-4 \frac{a^{2}}{r^{2}}+3 \frac{a^{4}}{r^{4}}\right) \cos 2 \theta\right] \\
\sigma_{\theta} & =\frac{P}{2}\left[(1+\lambda)\left(1+\frac{a^{2}}{r^{2}}\right)\right. \\
& \left.-(\lambda-1)\left(1+3 \frac{a^{4}}{r^{4}}\right) \cos 2 \theta\right] \\
\tau_{r \theta} & =\frac{P}{2}\left[(1-\lambda)\left(1+2 \frac{a^{2}}{r^{2}}-3 \frac{a^{4}}{r^{4}}\right) \sin 2 \theta\right]
\end{aligned}
$$

where $\sigma_{r}, \sigma_{\theta}$, and $\tau_{r \theta}$ are the radial, tangential, and shearing stresses, respectively, of every point in the coordinate system. After the material was destroyed, the original stresses were transferred and rebalanced. The stress state in the damaged area was the result of the original elastic stress being rebalanced after material failure and pressure relief. The failure mechanism revealed the cause of the damage; therefore, it is necessary to study the distribution law of the elastic stress field before the failure of the surrounding rock.

2.2. Three Elements of the Mohr Circle Determining the Material Failure. The purpose of studying the stress field is to determine the surrounding rock failure laws. The stress solutions around a circular cavity in formula (2) could not directly reflect these laws; therefore, it is meaningless to study stress solutions without considering the strength criterion. In this study, the Mohr-Coulomb strength theory was used, as shown in Figure 3, where $\sigma_{1}$ and $\sigma_{3}$ are the maximum and minimum principal stresses, respectively, of the element; $C$ is the rock cohesion; and $\varphi$ is the rock internal friction angle. According to the results from elastic mechanics studies $[25,36]$, the maximum and minimum principal stresses can be expressed as formula (3).

$$
\begin{aligned}
& \sigma_{1}=\frac{\sigma_{r}+\sigma_{\theta}}{2}+\frac{1}{2} \sqrt{\left(\sigma_{r}-\sigma_{\theta}\right)^{2}+4 \tau_{r \theta}^{2}} \\
& \sigma_{3}=\frac{\sigma_{r}+\sigma_{\theta}}{2}-\frac{1}{2} \sqrt{\left(\sigma_{r}-\sigma_{\theta}\right)^{2}+4 \tau_{r \theta}^{2}}
\end{aligned}
$$

Different stress states lead to different abilities for destroying a rock. The materials have the strength to overcome the stress, and, accordingly, the stresses also have the abilities to destroy the material. Therefore, the concept of stress destructive power is proposed in this paper. This power indicates the damage capacity of different stresses to the same material under the condition of the Mohr-Coulomb strength criterion. In a single direction, the stress size can measure the stress destructive power. However, under the condition of the Mohr-Coulomb strength criterion, the stress size in 


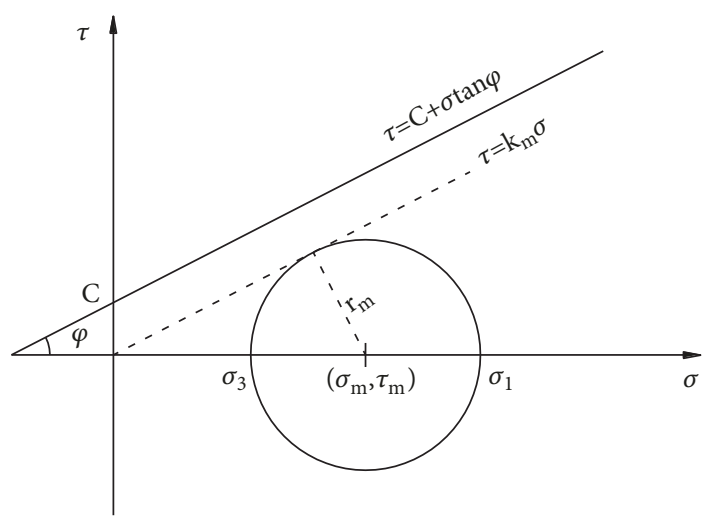

FIGURE 3: Diagram of the Mohr-Coulomb strength criterion.

a single direction cannot measure the destructive power of the stress state. For example, under the condition of the same rock material, when the maximum and minimum principal stresses at a particular point are both large, the Mohr circle radius is small and the centre coordinate is large. The Mohr circle does not easily intersect with the strength envelope of the material; therefore, the stress has little destructive power. The rock destruction is determined by the relative position of the stress Mohr circle and by the strength envelope of the rock material: the elements are destroyed when they intersect or are tangent to one another and are in the elastic state when they are separated. The centre coordinates, radius, and tangent slope through the origin of the Mohr circle determine its properties; since these parameters directly reflect the stress destructive power, they are called the three elements of the Mohr circle and they determine the material failure.

(1) The Mohr Circle Centre Coordinates. In Figure 3, under the condition of a certain radius, the smaller the centre abscissa is, the easier the Mohr circle intersects with the strength envelope of the material, and the greater the stress destructive power is. The abscissa and ordinate of the Mohr circle centre can be represented by $\sigma_{m}$ and $\tau_{m}$, respectively, as expressed in formula (4).

$$
\begin{aligned}
\sigma_{m} & =\frac{\sigma_{1}+\sigma_{3}}{2} \\
\tau_{m} & =0
\end{aligned}
$$

(2) The Mohr Circle Radius. In Figure 3, under the condition of a certain centre, the greater the radius is, the easier the Mohr circle intersects with the strength envelope of the material, and the greater the stress destructive power is. The Mohr circle radius can be represented by $r_{m}$, as expressed in formula (5).

$$
r_{m}=\frac{\sigma_{1}-\sigma_{3}}{2}
$$

(3) The Tangent Slope through the Origin of the Mohr Circle. In Figure 3, when the Mohr circle centre moves or the radius changes, the tangent slope through the origin will be changed. When the centre and the radius are not fixed, the stress destructive power can be evaluated by the tangent slope through the origin. The Mohr circle tangent slope through the origin can be represented by $k_{m}$, as expressed in formula (6).

$$
k_{m}=\frac{\sigma_{1}-\sigma_{3}}{2 \sqrt{\sigma_{1} \sigma_{3}}}
$$

The three elements of the Mohr circle determine the relative position of the stress Mohr circle and the strength envelope of the rock material and can be used to evaluate the stress destructive power.

2.3. Distribution Characteristics of the Circumferential Stress Field. The sharp-point failure of the rock surrounding a circular cavity is related to the distribution characteristics of the stress field around the cavity. According to the above analysis, the three elements of the Mohr circle can be used to evaluate the stress destructive power. The distribution laws of these elements will be studied below, and those of the stress destructive power around the circular cavity will be presented.

The stress distribution laws are studied by confirming the stress state of each point in the space position, and a different spatial arrangement will produce a different result of the stress distribution. The nonuniform characteristics of the sharp-point failure zone of the surrounding rock are measured with the circular outline of the cavity. Namely, the failure zone of the rock surrounding is located in the local area around the cavity. Therefore, the circumferential direction around the circular cavity is taken as a spatial layout.

The plane strain stress model of the rock surrounding a circular cavity in Figure 2 is an axial symmetrical model; therefore, it is only needed to study the distribution laws of the stress field in the first quadrant. The polar coordinate $\theta$ needs to satisfy formula (7).

$$
0 \leq \theta \leq \frac{\pi}{2}
$$

2.3.1. Distribution of the Mohr Circle Centre Coordinates. According to formula (4), the ordinate of the Mohr circle centre is always 0 , and it is only needed to study the abscissa distribution laws. On the basis of formulas (2), (3), and (4), the expression for the Mohr circle centre abscissa is obtained.

$$
\sigma_{m}(\theta)=-P(\lambda-1)\left(\frac{a^{2}}{r^{2}}\right) \cos 2 \theta+\frac{P(1+\lambda)}{2}
$$

Figures 4 and 5 are the $\sigma_{m}(\theta)$ distribution curves in different radius circumferential positions around a cavity with a fixed side pressure coefficient $(\lambda=3)$, and under the condition of different side pressure coefficient with fixed radius circumferential positions $(r=3 a)$, respectively. Formula (8) contains the common factor $\mathrm{P}$ in each of the items; therefore, the multiple of $P$ is used as the ordinate in the figures. According to Figure $4, \sigma_{m}(\theta)$ increases monotonously with $\theta$ in the range of $r / a=2$ to $r / a=10$. Similarly, according to Figure $5, \sigma_{m}(\theta)$ 


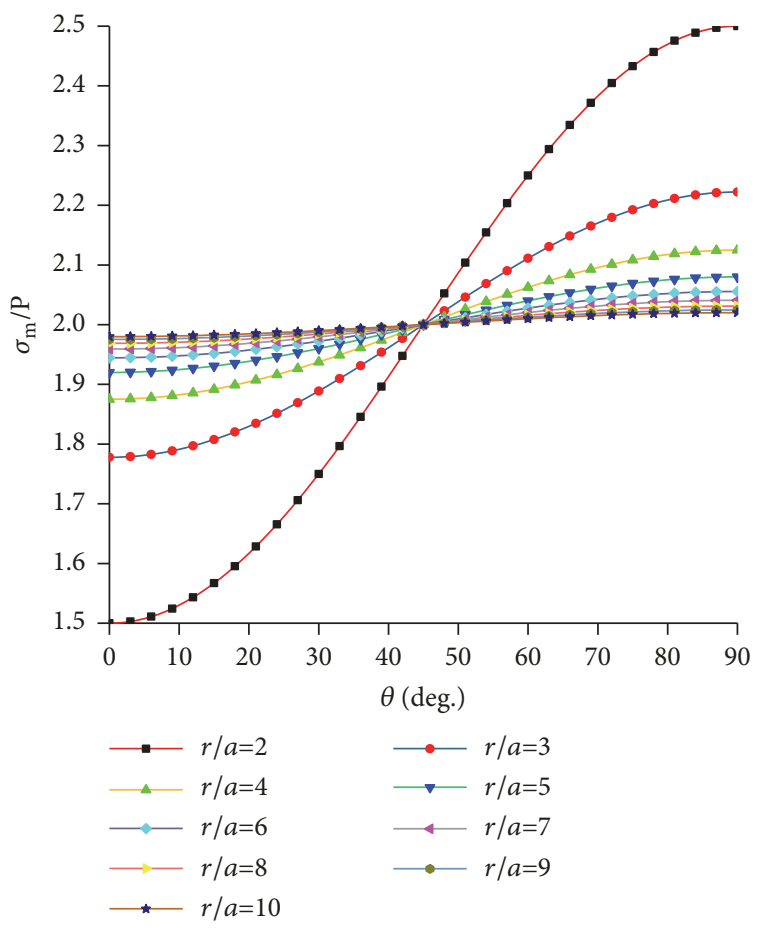

Figure 4: Abscissa distribution curves of the Mohr circle centre in different radius circumferential positions around a cavity.

increases monotonously with $\theta$ from $\lambda=1.5$ to $\lambda=5$. According to formula (8), under a determined ground stress condition, the vertical and horizontal stresses are certain, $P$ and $\lambda$ are constant, the function $\cos 2 \theta$ decreases monotonically on the domain $(0, \pi / 2)$, and $\sigma_{m}(\theta)$ increases monotonically on the domain in the circumferential direction with any radius. Therefore, the function $\sigma_{m}(\theta)$ increases monotonically on the domain $(0, \pi / 2)$ in the circumferential direction with any radius and under the condition of an arbitrary stress environment.

2.3.2. Distribution of the Mohr Circle Radius. On the basis of formulas (2), (3), and (5), the expression of the Mohr circle radius can be expressed as

$$
r_{m}(\theta)=\frac{P}{2} \sqrt{A_{1} \cos ^{2} 2 \theta+B_{1} \cos 2 \theta+C_{1}}
$$

where,

$$
\begin{aligned}
& A_{1}=(\lambda-1)^{2}\left(\frac{24 a^{6}}{r^{6}}+\frac{12 a^{4}}{r^{4}}\right) ; \\
& B_{1}=2\left(\lambda^{2}-1\right)\left(\frac{3 a^{6}}{r^{6}}+\frac{2 a^{4}}{r^{4}}+\frac{a^{2}}{r^{2}}\right) ; \\
& C_{1}=-2\left(\lambda^{2}-4 \lambda+1\right) \frac{a^{4}}{r^{4}}+2(\lambda-1)^{2} \frac{a^{2}}{r^{2}}+(\lambda-1)^{2} .
\end{aligned}
$$

Figures 6 and 7 are the $r_{m}(\theta)$ distribution curves in different radius circumferential positions around a cavity with a fixed side pressure coefficient $(\lambda=3)$, and under the condition

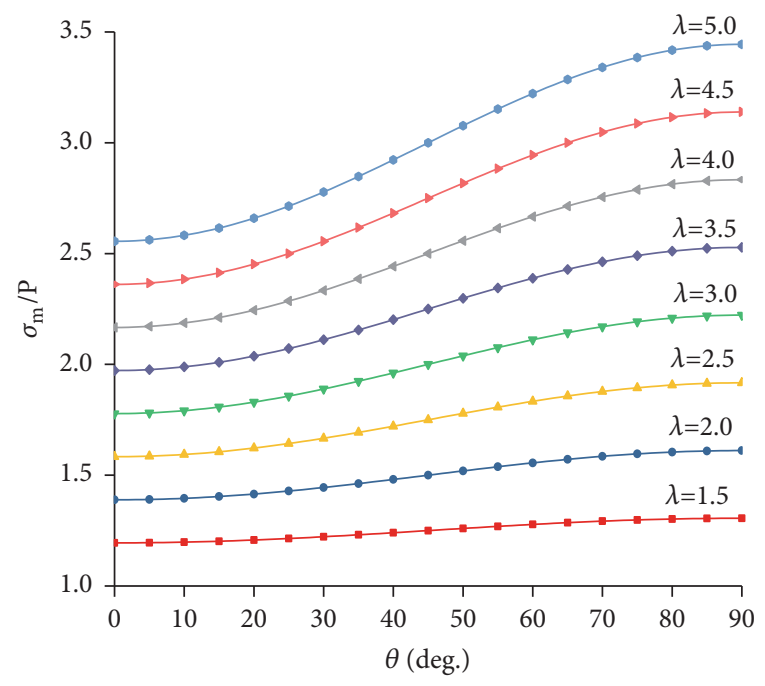

FIgURE 5: Abscissa distribution curves of the Mohr circle centre under the condition of different side pressure coefficients.

of different side pressure coefficients with fixed radius circumferential positions $(r=3 a)$. According to Figure $6, r_{m}(\theta)$ increases first and then decreases with $\theta$ increasing in the range of $r / a=2$ to $r / a=10$. Similarly, based on Figure 7 , the $r_{m}(\theta)$ increases first and then decreases with $\theta$ increasing from $\lambda=1.5$ to $\lambda=5$. In formula (9), $A_{1}>0$, the function $A_{1} \cos ^{2} 2 \theta+B_{1} \cos 2 \theta+C_{1}$ is an upward parabolic function of $\cos 2 \theta$, and the function $\cos 2 \theta$ decreases monotonically on the domain $(0, \pi / 2)$. Therefore, the function $r_{m}(\theta)$ is a convex function on the domain $(0, \pi / 2)$ in the circumferential direction with any radius and under the condition of an arbitrary stress environment.

2.3.3. Distribution of the Mohr Circle Tangent Slope through the Origin. On the basis of formulas (2), (3), and (6), the expression of the Mohr circle tangent slope through the origin can be expressed as

$$
k_{m}(\theta)=\frac{\sqrt{A_{1} \cos ^{2} 2 \theta+B_{1} \cos 2 \theta+C_{1}}}{\sqrt{A_{2} \cos ^{2} 2 \theta+B_{2} \cos 2 \theta+C_{2}}}
$$

where,

$$
\begin{aligned}
A_{2}= & (\lambda-1)^{2}\left(-\frac{8 a^{2}}{r^{2}}+\frac{8 a^{2}}{r^{2}}\right) ; \\
B_{2}= & \left(\lambda^{2}-1\right)\left(-\frac{4 a^{4}}{r^{4}}-\frac{2 a^{2}}{r^{2}}\right) ; \\
C_{2}= & (\lambda-1)^{2}\left(-\frac{9 a^{8}}{r^{8}}+\frac{12 a^{6}}{r^{6}}-\frac{4 a^{2}}{r^{2}}\right) \\
& +\left(\lambda^{2}-6 \lambda+1\right) \frac{a^{4}}{r^{4}}+4 \lambda .
\end{aligned}
$$

Figures 8 and 9 are the $k_{m}(\theta)$ distribution curves in different radius circumferential positions around a cavity 


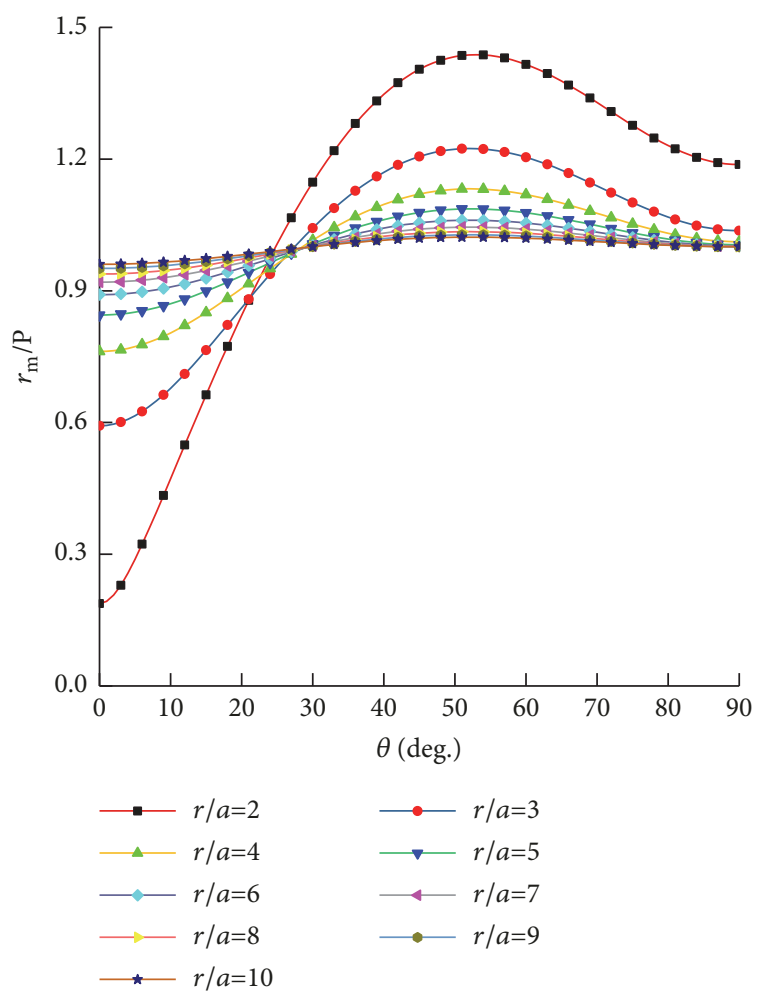

Figure 6: Distribution curves of the Mohr circle radius in different radius circumferential positions around a cavity.

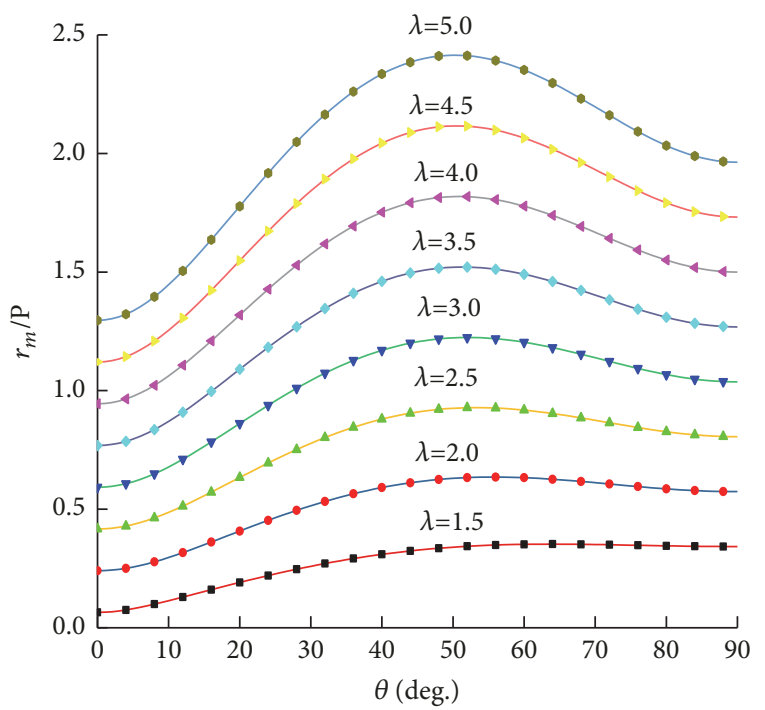

FIgURE 7: Distribution curves of the Mohr circle radius under the condition of different side pressure coefficients.

with a fixed side pressure coefficient $(\lambda=3)$, and under the condition of different side pressure coefficients with fixed radius circumferential positions $(r=3 a)$. According to Figure $8, k_{m}(\theta)$ increases first and then decreases with $\theta$ increasing in the range of $r / a=2$ to $r / a=10$. Similarly, according to Figure $9, k_{m}(\theta)$ increases first and then decreases with

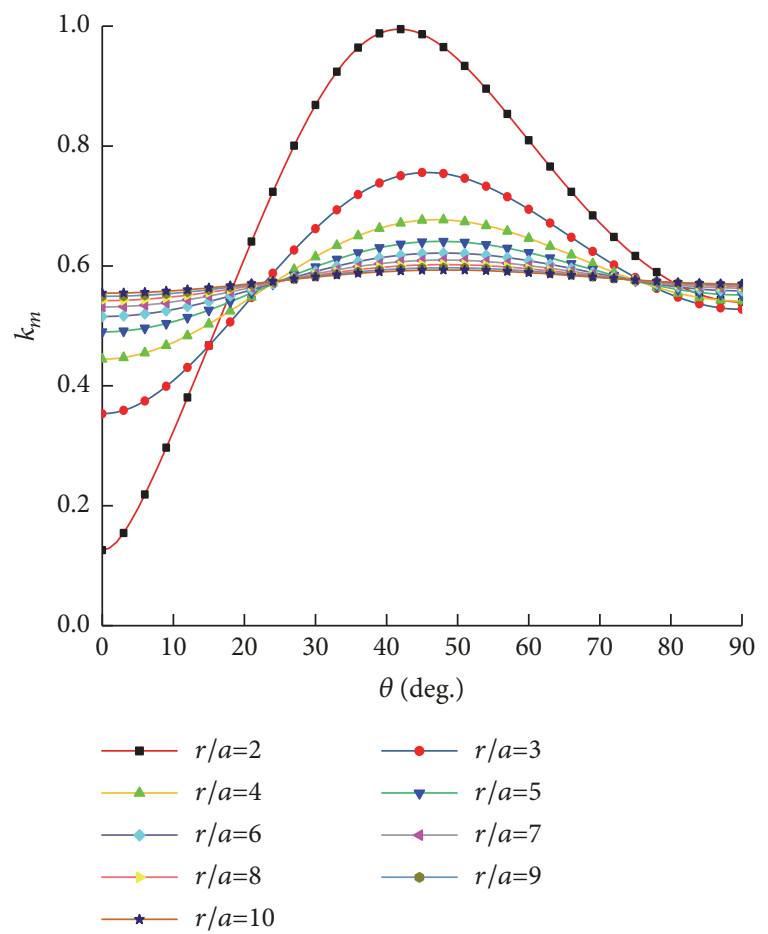

Figure 8: Tangent slope of the Mohr circle through the origin distribution curves in different radius circumferential positions around a cavity.

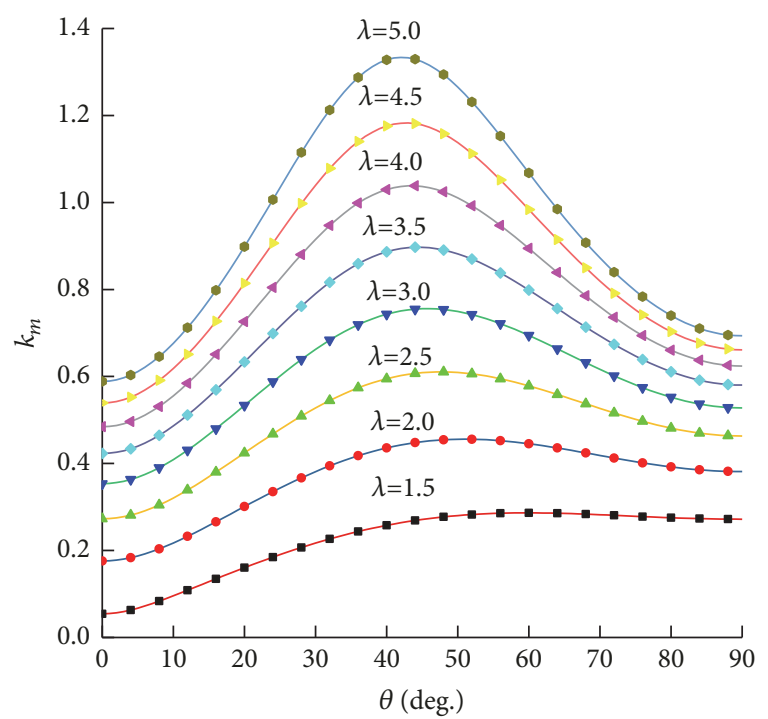

FIgURE 9: Tangent slope of the Mohr circle through the origin distribution curves under the condition of different side pressure coefficients.

$\theta$ increasing from $\lambda=1.5$ to $\lambda=5$. Presumably, the function $k_{m}(\theta)$ is a convex function on the domain $(0, \pi / 2)$ in the circumferential direction with any radius and under the condition of an arbitrary stress environment. 


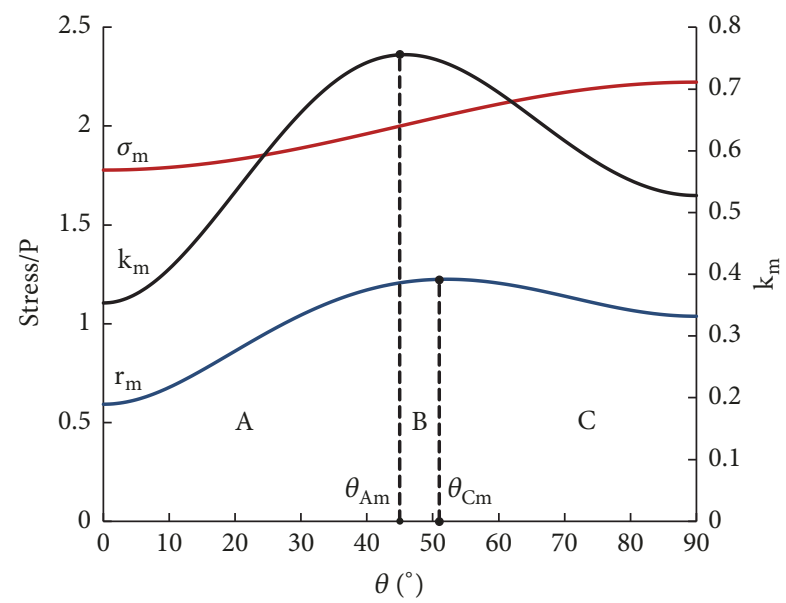

Figure 10: Circumferential partition of the stress field around a circular cavity.

\section{Mechanism of the Sharp-Point Failure of the Rock Surrounding a Circular Cavity}

The stress field around a circular cavity has obvious distribution characteristics in the circumferential direction. In an arbitrarily determined ring position, from 0 to $\pi / 2, \sigma_{m}(\theta)$ increases monotonically, and $r_{m}(\theta)$ and $k_{m}(\theta)$ are convex functions that increase first and then decrease gradually with a maximum point. The stress field distribution law around a circular cavity determines the sharp-point failure characteristics of the surrounding rock. The mechanism of the sharp-point failure will be illustrated in detail.

According to the distribution law of the stress field around a circular cavity, in an arbitrarily determined ring position, from 0 to $\pi / 2$, the stress field is divided into three regions, as shown in Figure 10. The polar angles corresponding to the maximum points on the $k_{m}(\theta)$ and $r_{m}(\theta)$ curves are recorded as $\theta_{A m}$ and $\theta_{C m}$, respectively. With $\theta_{A m}$ and $\theta_{C m}$ as the dividing lines, the stress field around a circular cavity is divided into three regions, namely, $\mathrm{A}, \mathrm{B}$, and $\mathrm{C}$.

According to the diagram of the Mohr-Coulomb strength criterion in Figure 3, the monotonicity of the functions $r_{m} / \sigma_{m}$ and $k_{m}$ is the same. $\sigma_{m}(\theta)$ increases monotonically, and $r_{m}(\theta)$ increases first and then decreases; therefore, the maximum point on the $r_{m} / \sigma_{m}$ curve must appear before the maximum point on the $k_{m}$ curve.

$$
\theta_{A m}<\theta_{C m}
$$

With $\theta_{A m}$ and $\theta_{C m}$ as the dividing lines, the stress field around a circular cavity is divided into three regions: the range of region $A$ meets the condition of $0 \leq \theta<\theta_{A m}$, the range of region $\mathrm{B}$ meets the condition of $\theta_{A m} \leq \theta \leq \theta_{C m}$, and the range of region $C$ meets the condition of $\theta_{C m}<\theta \leq \pi / 2$. The stress destructive power characteristics of the stress field in different regions will be analysed in detail as follows.

(1) Analysis of the Stress Destructive Power in Region A. Let $\mathrm{A} 1$ and A2 be any two points on the same circumferential position in region $\mathrm{A}$, and let the corresponding polar angles

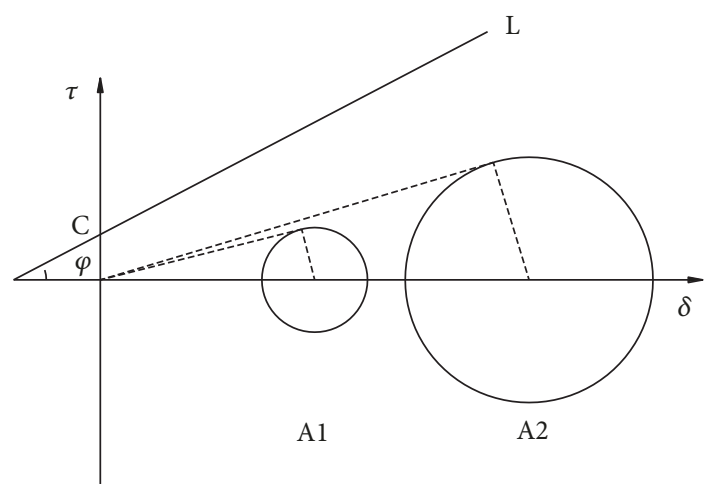

FIGURE 11: Discrimination diagram of the stress destructive power in region $\mathrm{A}$.

be $\theta_{A 1}$ and $\theta_{A 2}$, respectively, satisfying the condition $\theta_{A 1}<$ $\theta_{A 2}$. According to the circumferential partition of the stress field around the circular cavity in Figure 10, the functions $\sigma_{m}, r_{m}$, and $k_{m}$ all increase monotonically in region $\mathrm{A}$; therefore, the following conditions are met: $\sigma_{m}\left(\theta_{A 1}\right)<\sigma_{m}\left(\theta_{A 2}\right)$, $r_{m}\left(\theta_{A 1}\right)<r_{m}\left(\theta_{A 2}\right)$, and $k_{m}\left(\theta_{A 1}\right)<k_{m}\left(\theta_{A 2}\right)$. The discrimination diagram of the stress destructive power in region $\mathrm{A}$ was obtained, as shown in Figure 11. As we all know, the rock cohesion is greater than 0 ; for any rock material that is likely to be damaged at points $\mathrm{A} 1$ and $\mathrm{A} 2$, its shear envelope line $\mathrm{L}$ must intersect first with the Mohr circle at point A2. Any rock material will take precedence over failure under the stress condition at point A2. The stress destructive power at point $\mathrm{A} 2$ is stronger than that at point A1. Since A1 and A2 are any two points on the same circumferential position in region $\mathrm{A}$, the stress destructive power of a field in region A is gradually enhanced with the increase in the polar angle.

(2) Analysis of the Stress Destructive Power in Region C. Let $\mathrm{C} 1$ and $\mathrm{C} 2$ be any two points on the same circumferential position in region $\mathrm{C}$, and let the corresponding polar angles be $\theta_{C 1}$ and $\theta_{C 2}$, respectively, satisfying the condition $\theta_{C 1}<$ $\theta_{C 2}$. According to the circumferential partition of the stress field around a circular cavity in Figure 10, the function $\sigma_{m}$ decreases monotonically in region $\mathrm{C}$, and the functions $r_{m}$ and $k_{m}$ both decrease monotonically; therefore, the following conditions are met: $\sigma_{m}\left(\theta_{C 1}\right)<\sigma_{m}\left(\theta_{C 2}\right), r_{m}\left(\theta_{C 1}\right)>r_{m}\left(\theta_{C 2}\right)$, and $k_{m}\left(\theta_{C 1}\right)>k_{m}\left(\theta_{C 2}\right)$. A discrimination diagram of the stress destructive power in region $\mathrm{C}$ was made, as shown in Figure 12. Because the rock cohesion is greater than 0 , for any rock material that is likely to be damaged at points $\mathrm{Cl}$ and $\mathrm{C} 2$, its shear envelope line L must intersect first with the Mohr circle at point $\mathrm{Cl}$. Any rock material will take precedence over failure under the stress condition at point Cl. Namely, the stress destructive power at point $\mathrm{Cl}$ is stronger than that at point $\mathrm{C}$. Since $\mathrm{C} 1$ and $\mathrm{C} 2$ are any two points on the same circumferential position in region $\mathrm{C}$, the stress destructive power of the stress field in region $\mathrm{C}$ is gradually weakened with the increase in the polar angle.

(3) Analysis of the Stress Destructive Power in Region B. Let $\mathrm{B} 1$ and $\mathrm{B} 2$ be any two points on the same circumferential 


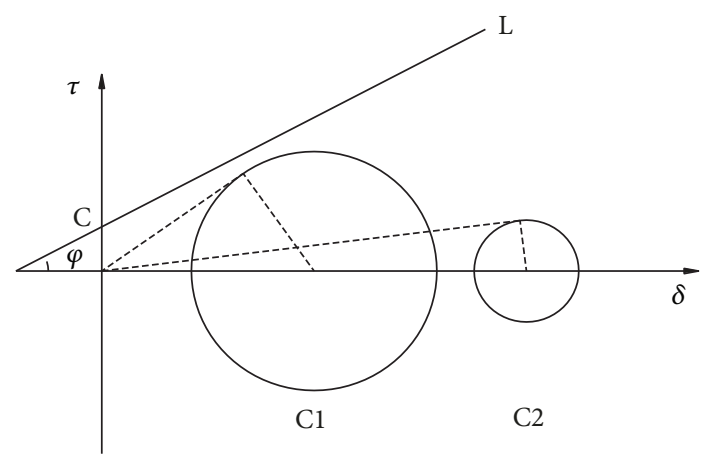

Figure 12: Discrimination diagram of the stress destructive power in region $\mathrm{C}$.

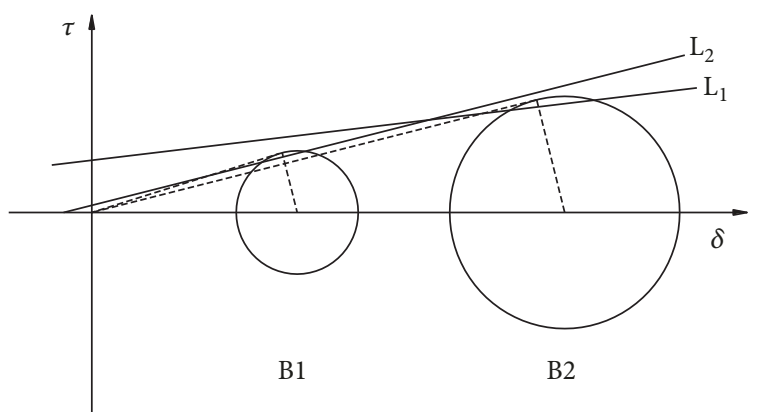

FIGURE 13: Discrimination diagram of the stress destructive power in region $\mathrm{B}$.

position in region $\mathrm{B}$, and let the corresponding polar angles be $\theta_{B 1}$ and $\theta_{B 2}$, respectively, satisfying the condition $\theta_{B 1}<$ $\theta_{B 2}$. According to the circumferential partition of the stress field around a circular cavity in Figure 10, the functions $\sigma_{m}$ and $r_{m}$ decreases monotonically in region $\mathrm{B}$ and the function $k_{m}$ decreases monotonically; therefore, the following conditions are met: $\sigma_{m}\left(\theta_{B 1}\right)<\sigma_{m}\left(\theta_{B 2}\right), r_{m}\left(\theta_{B 1}\right)<r_{m}\left(\theta_{B 2}\right)$, and $k_{m}\left(\theta_{B 1}\right)>k_{m}\left(\theta_{B 2}\right)$. The discrimination diagram of the stress destructive power in region $B$ is shown in Figure 13.

In Figure 13, the Mohr circle radius at point B1 is smaller, whereas the Mohr circle tangent slope through the origin is greater. The shear envelope line $\mathrm{L}_{1}$ of rock material will intersect first with the Mohr circle at point B2, whereas the shear envelope line $\mathrm{L}_{2}$ of this material will intersect first with the Mohr circle at point B1. The relative strength of the stress destructive power at points B1 and B2 cannot be determined directly according to the inherent properties of the rock material.

The relative strength of the stress destructive power at points $\mathrm{B} 1$ and $\mathrm{B} 2$ cannot be determined by the relative size of the slope between the shear envelope of rock material and the common tangent of two Mohr circles, as shown in Figure 14. When the slope of shear envelope $\mathrm{L}_{2}$ of the rock material is greater than that of the common tangent $\mathrm{L}$ of two Mohr circles, $\mathrm{L}_{2}$ will intersect first with the Mohr circle at point B1; therefore, the stress destructive power at point $\mathrm{B} 1$ is stronger than that at point B2. When the slope of the shear envelope $L_{1}$ of the rock material is less than that of the common tangent

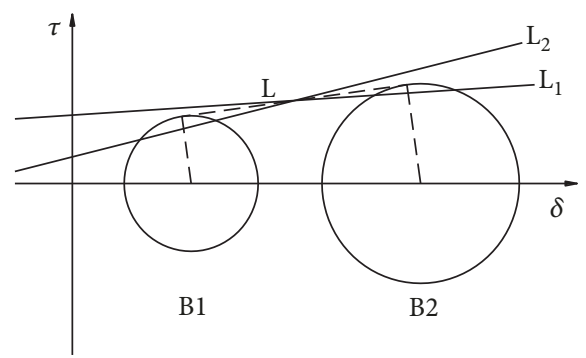

FIGURE 14: Discrimination diagram of the stress destructive power for any two points in region $\mathrm{B}$.

L of two Mohr circles, $\mathrm{L}_{1}$ will intersect first with the Mohr circle at point B2; therefore, under this condition the stress destructive power at point $\mathrm{B} 2$ is stronger than that at point B1. According to the discrimination method of the stress destructive power for any two points in region $\mathrm{B}$, the point with the strongest stress destructive power of the stress field in region B can be found.

In a certain circumferential position, the stress destructive power of the stress field in region A is gradually enhanced with the increase in the polar angle, whereas that in region $\mathrm{C}$ is gradually weakened with the increase in the polar angle. Since the three elements of the Mohr circle are continuous functions of the polar angle, the point with the strongest stress destructive power of the stress field must be located in region $\mathrm{B}$. The polar angle corresponding to the point with the strongest stress destructive power on the circumferential position of $r$ away from the cavity centre is defined as the stress sharp-point polar angle, which is expressed by $\theta_{t}(r)$. The stress sharp-point angle is a function of the distance to the cavity centre, and a different circumferential position will correspond to a different stress sharp-point angle, as expressed in formula (14).

$$
\theta_{A m}(r) \leq \theta_{t}(r) \leq \theta_{C m}(r)
$$

Under the determined stress conditions, the circular cavity radius $a$, the vertical stress $P$, and the lateral pressure coefficient $\lambda$ are all constants, and $\theta_{A m}(r)$ and $\theta_{C m}(r)$ need to satisfy (15) and (16), respectively.

$$
\begin{aligned}
& \frac{\partial k_{m}(r, \theta)}{\partial \theta}=0 \\
& \frac{\partial r_{m}(r, \theta)}{\partial \theta}=0
\end{aligned}
$$

(4) Mechanism of the Sharp-Point Failure in Rocks Surrounding a Circular Cavity. In the nonuniform stress field under the ground, the stresses around a circular cavity show similar distribution characteristics at different circumferential locations: in an arbitrarily determined circumferential position, from 0 to $\pi / 2$, the stress destructive power is gradually enhanced and then weakened with the increase in the polar angle, showing a sharp-angular distribution, and there is a stress sharp point with the strongest stress destructive power. Rock material with any properties will be destroyed first in 


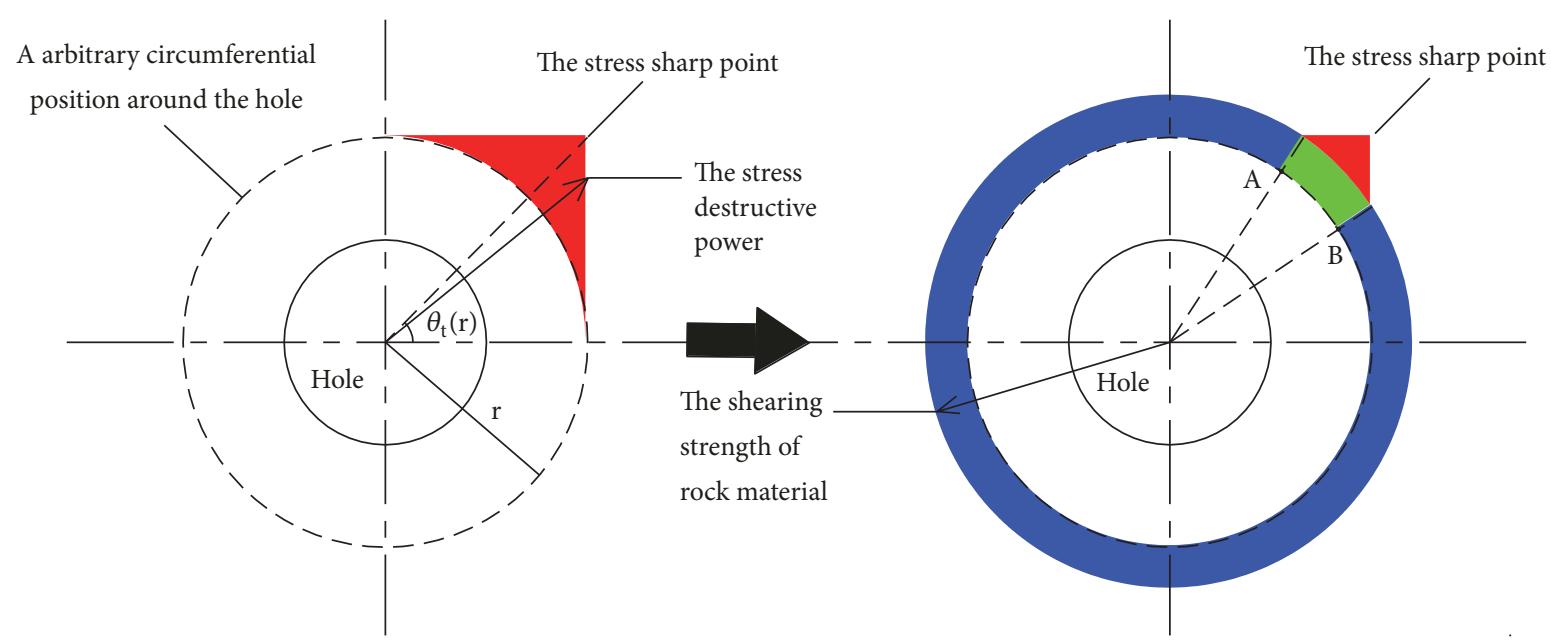

(a) Mechanism diagram of the sharp-point failure of the rock surrounding a circular cavity

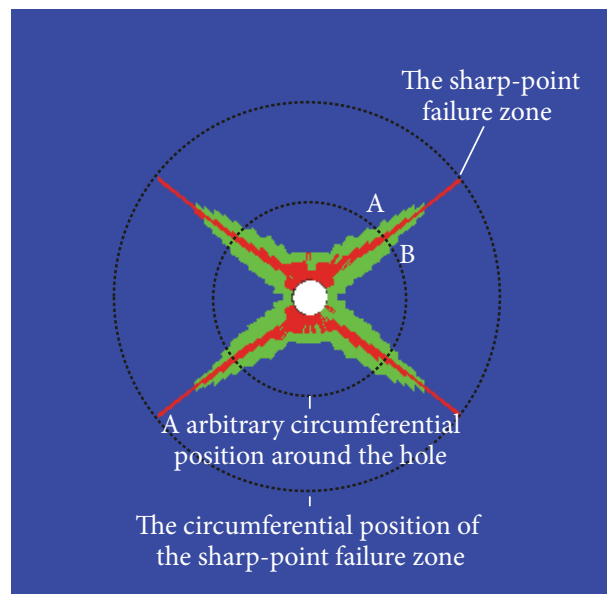

(b) Specific example of the sharp-point failure of the rock surrounding a circular cavity

FIGURE 15: Mechanism of the sharp-point failure of rock surrounding a circular cavity.

the place where the stress destructive power is stronger. This is the mechanism of sharp-point failure in the rock surrounding a circular cavity, as shown in Figure 15(a).

In Figure 15(a), the solid circle represents the boundary of the circular cavity; the broken circle represents an arbitrary circumferential position around the cavity and the red area represents the stress destructive power in the circumferential position from 0 to $\pi / 2$ (the stress destructive power is given by the length from the cavity centre to the red area boundary under the same polar angle, showing a sharpangular distribution from 0 to $\pi / 2$ ). The blue area represents the shearing strength of the rock material (the shearing strength of the rock material is expressed by the length from the cavity centre to the blue area boundary, and the certain rock material has a particular shear strength; therefore, the blue area is a circular ring with an uniform distribution). The green area represents the rock failure zone (when the stress destructive power is greater than the shearing strength of the rock material, the rock material is destroyed). In the circumferential direction, the rock material would be destroyed near the stress sharp point, whereas that on the two sides is still in the elastic state owing to the weak stress destructive power. In the radial direction, according to Figures 6 and 8, the stress destructive power of the stress sharp point in each circumferential direction is gradually weakened with the increase in the distance to the cavity centre, with the red area that goes beyond the blue area being smaller and smaller and the rock failure zone being narrower and narrower, and, in the end, failure occurs only at the stress sharp point at a certain circumferential position. The sharp-point failure of the rock surrounding a circular cavity is formed, as shown in Figure 15(b).

\section{Directional Distribution Characteristics of the Stress Sharp Points}

According to the mechanism of the sharp-point failure of the rock surrounding a circular cavity, the sharp-point failure zone is the stress sharp point at the same circumferential position. The expansion direction of the rock surrounding a 
failure zone under the stress field around a circular cavity is always consistent with the direction of the stress sharp-point polar angle at the circumferential position. To determine the expansion direction of the rock surrounding a failure zone, we studied the distribution law of the stress sharp-point polar angle around a circular cavity. According to formula (14), the stress sharp-point polar angle $\theta_{t}(r)$ is determined by the polar angles corresponding to the maximum points on the $k_{m}(\theta)$ and $k_{m}(\theta)$ curves, $\theta_{A m}(r)$ and $\theta_{C m}(r)$. Therefore, we can study the distribution laws of $\theta_{A m}(r)$ and $\theta_{C m}(r)$ to learn about the distribution laws of the stress sharp-point polar angle and the expansion direction of the rock surrounding a failure zone.

According to formulas (15) and (16), $\theta_{A m}(r)$ and $\theta_{C m}(r)$ in an arbitrary circumferential position under an arbitrary stress condition can be calculated. The radial, tangential, and shearing stresses of every point in formula (2) all contain the $P$ factor; therefore, the vertical stress $P$ only affects the size of $r_{m}$ and $k_{m}$ and does not affect the location of their maximum points. At the same time, all of the parameters for $r$ in formula (2) are expressions of $r / a$; therefore, the impact of the circular cavity radius does not need to be studied separately and $r / a$ can be used to represent the distance from the circumferential position to the cavity centre. The lateral pressure coefficient $\lambda$ and the distance to the cavity centre $r / a$ are the only two factors that affect $\theta_{A m}(r)$ and $\theta_{C m}(r)$; therefore, the stress sharp-point polar angle criterion can be expressed as follows.

$$
\theta_{A m}\left(\frac{r}{a}, \lambda\right) \leq \theta_{t}\left(\frac{r}{a}, \lambda\right) \leq \theta_{C m}\left(\frac{r}{a}, \lambda\right)
$$

Here, $\theta_{A m}(r / a, \lambda)$ and $\theta_{C m}(r / a, \lambda)$ need to satisfy (18) and (19), respectively.

$$
\begin{aligned}
& \frac{\partial k_{m}(\lambda, r / a, \theta)}{\partial \theta}=0 \\
& \frac{\partial r_{m}(\lambda, r / a, \theta)}{\partial \theta}=0
\end{aligned}
$$

According to formulas (9), (11), (18), and (19), $\theta_{A m}$ and $\theta_{C m}$ in an arbitrary circumferential position under an arbitrary stress condition can be calculated, and the stress sharp-point polar angle can also be determined. The distribution of $\theta_{A m}$ and $\theta_{C m}$ can be obtained by theoretical calculation under the conditions that the lateral pressure coefficient varies from 2 to 10 and that the influence range of the circular cavity varies from 2 to 40 times the cavity radius, as shown in Figure 16. The following results can be obtained from Figure 16:

(i) In the nonuniform stress field, the distributions of $\theta_{A m}$ and $\theta_{C m}$ show a similar convergent characteristic under a different lateral pressure coefficient; namely, the values of $\theta_{A m}$ and $\theta_{C m}$ almost no longer change after the distance to the cavity centre exceeds five times the cavity radius.

(ii) The difference between the convergent values of $\theta_{A m}$ and $\theta_{C m}$ is very small, and the maximum difference is within $5^{\circ}$. The error of the stress sharp-point angle determined by formula (17) is within $2.5^{\circ}$, and it is reliable to determine the stress sharp-point position by using formula (17).

(iii) According to the convergent characteristic of $\theta_{A m}$ and $\theta_{C m}$, it is speculated that the stress sharp-point angle will also be stable after the distance to the cavity centre exceeds five times the cavity radius. The distribution of the stress sharp points has directionality characteristics that are more than five times the cavity radius.

Formula (2) is the stress solution around a circular cavity obtained with the rock in the fully elastic state. After the destruction of the rock material, the failure unit will enter the residual stress stage, and the stress in the failure area will be attenuated. Therefore, in this study, the elastic stress was used to measure the stress destructive power of the stress field around a circular cavity before the rock failure and then to predict how the failure zone would expand. To prove the reliability of the theoretical calculation of the stress sharp-point angle around a circular cavity by formula (17), we studied the sharp-point distribution laws of the elastic damage zone. The elastic damage zone is a damage area determined by the strength criterion without considering the effect of the damage zone on the elastic stress field $[25,36]$. Therefore, the sharp-point position of the elastic damage zone is the position of the stress sharp point in the elastic stress field, as shown in Figure 17. In Figure 17, the stress sharppoint direction is expressed in $\theta_{t}$. According to Figure 16, the difference between the convergent values increases gradually with the increase in the lateral pressure coefficient. To prove the universal applicability of formula (17), we studied the distribution of the sharp point under the condition of uniaxial compression, as shown in Figure 17(c). The following results can be obtained from Figure 17:

(i) The stress sharp points around a circular cavity are all distributed between $\theta_{A m}$ and $\theta_{C m}$; therefore, it is reasonable to determine the position of the stress sharp point by using formula (17).

(ii) The difference between the convergent values of $\theta_{A m}$ and $\theta_{C m}$ is still very small under the condition of uniaxial compression, and the maximum error of the stress sharppoint angle determined by formula (17) is within $4^{\circ}$; therefore, formula (17) has universal applicability in the nonuniform stress field.

(iii) The stress sharp-point direction shows a convergent behaviour, and it tends to be stable at $40^{\circ}-50^{\circ}$ beyond five times the cavity radius.

The stress sharp-point angle shows an obvious convergence characteristic, indicating that the sharp-point failure around a circular cavity in a nonuniform stress field is directional. The stress sharp-point angle will be basically stable beyond five times the cavity radius, and the failure zone will also expand in a fixed direction. The directional sharp-point failure of the rock surrounding a circular cavity is directly determined by the distribution characteristics of the stress field around a circular cavity, and the rock with any material properties will suffer priority damage at the stress sharp point.

\section{Verification and Discussion}

The mechanism of the directional sharp-point failure of the rock surrounding a circular cavity in a nonuniform stress field was determined by theoretical analysis, and the FLAC ${ }^{3 \mathrm{D}}$ 


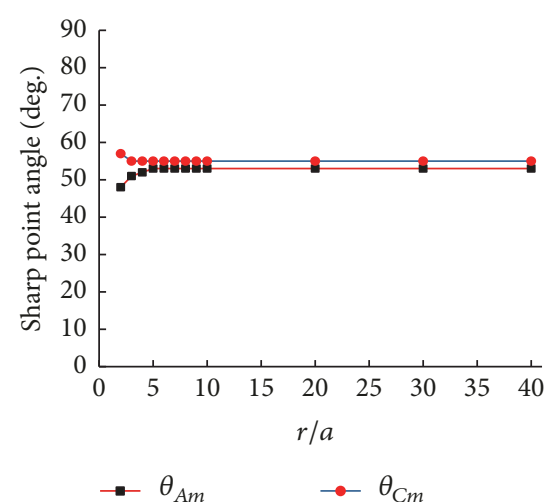

(1) $\lambda=2$

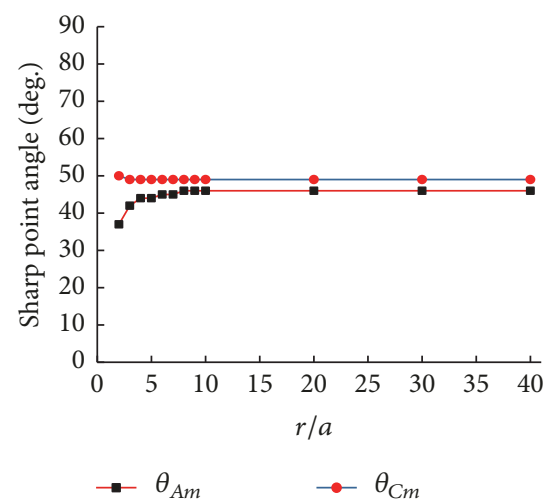

(4) $\lambda=5$

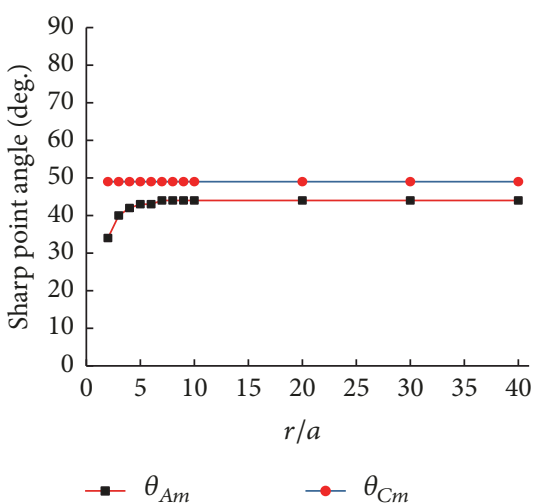

(7) $\lambda=8$

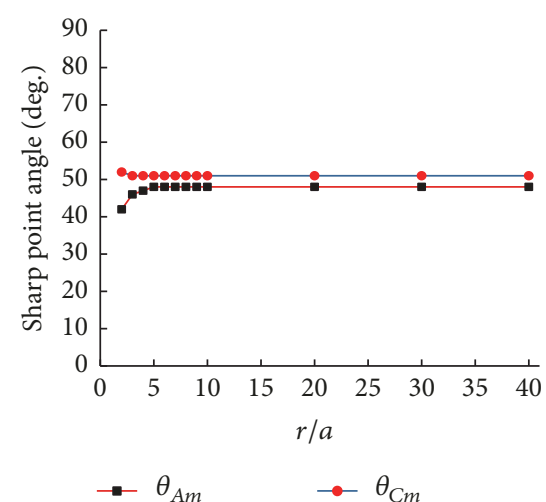

(2) $\lambda=3$

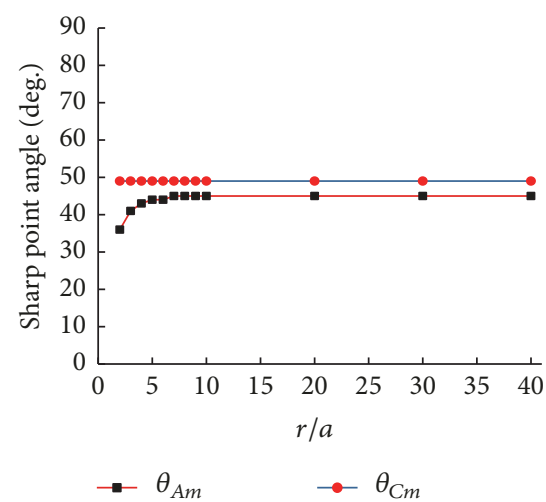

(5) $\lambda=6$

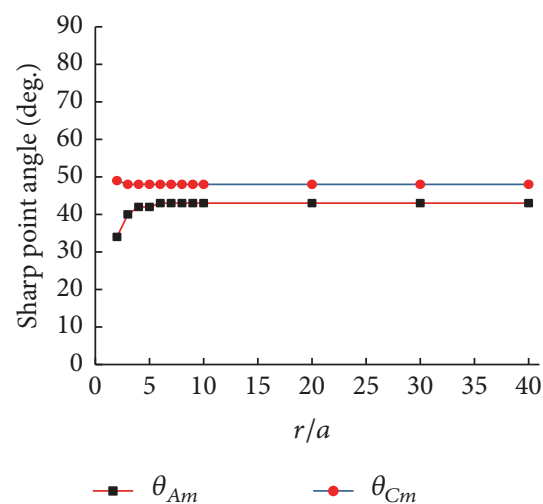

(8) $\lambda=9$

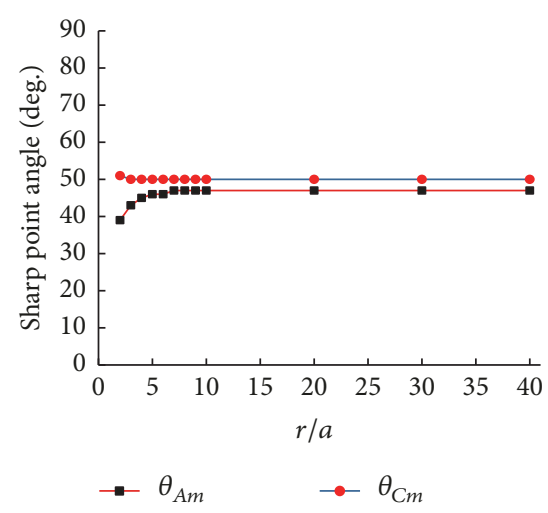

(3) $\lambda=4$

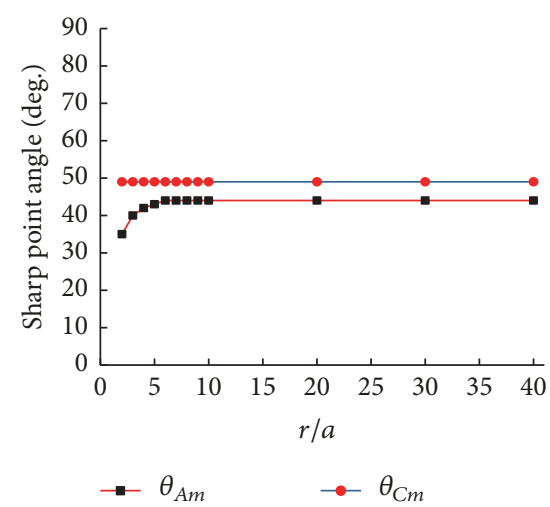

(6) $\lambda=7$

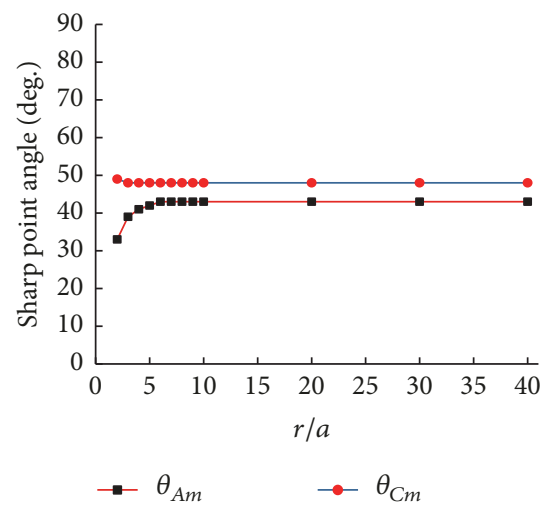

(9) $\lambda=10$

FIGURE 16: Diagram of the convergent characteristic of the stress sharp-point angle by theoretical calculation.

numerical simulation was used to verify the following three conclusions.

(1) Essence of the sharp-point failure: The sharp-point failure of the rock surrounding a circular cavity is completely determined by the special distribution of the stress field around the cavity, and it is independent of the rock properties. In a sufficiently strong stress field, the surrounding rock with any properties will form a sharp-point failure zone around a circular cavity.

(2) Directionality of the sharp-point failure zone: When the failure zone of the rock surrounding a circular cavity reaches a certain scope, the direction of the failure of the sharp-point angle tends to be stable and the failure zone will be expanded directionally.

(3) Sharp-point angle criterion: The sharp-point angle criterion has been determined by formulas (17), (18), and (19). It is necessary to verify the rationality of the factors determined by the criterion and the accuracy of the formula.

To verify the above three conclusions, we designed three numerical simulation schemes in this study, as shown in Figure 18. The first scheme proceeds as follows: Keeping the stress field unchanged, we studied the impact of rock material properties on the rock surrounding a sharp-point failure; the research indexes include the shapes of the plastic 


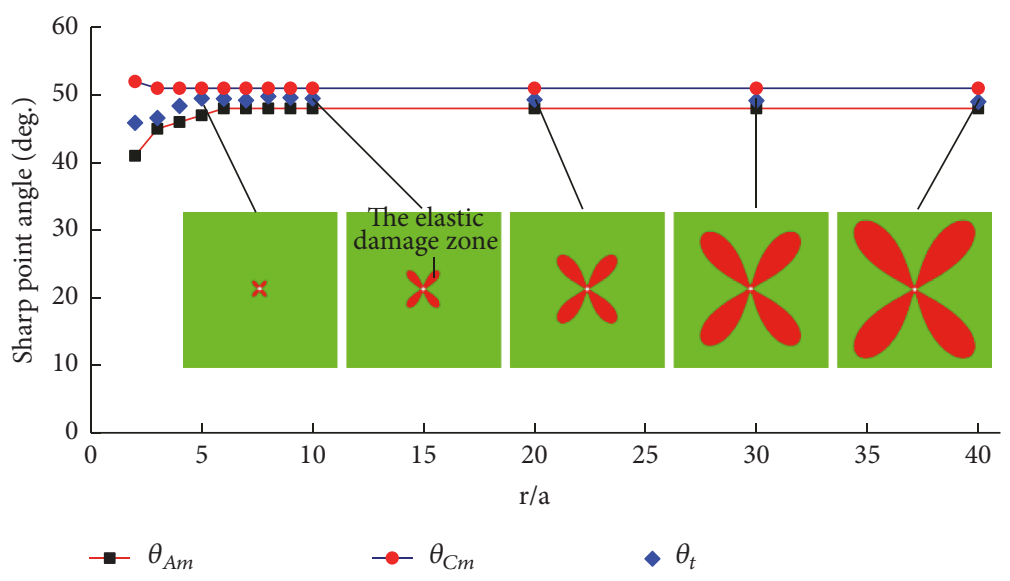

(a) $\lambda=3$

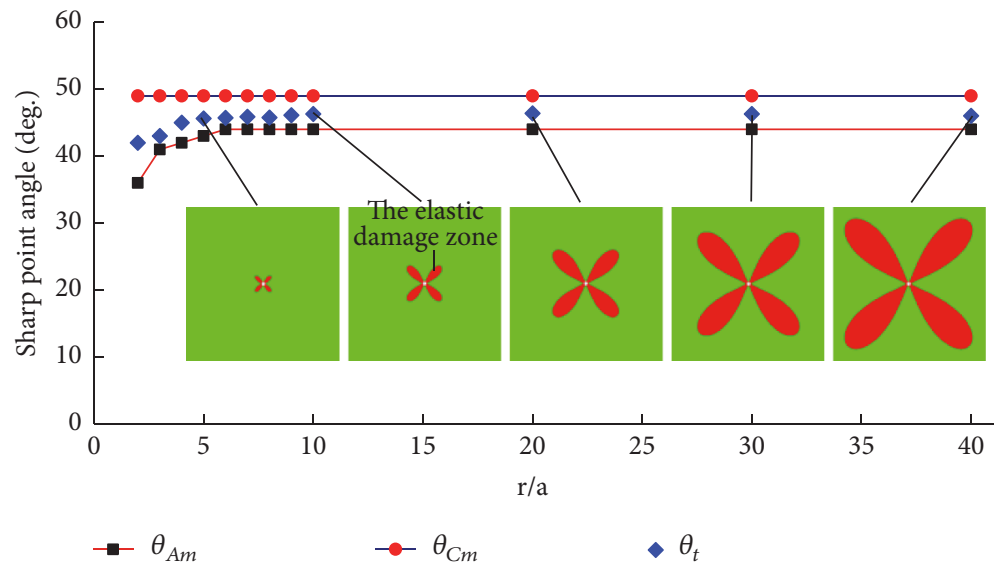

(b) $\lambda=6$

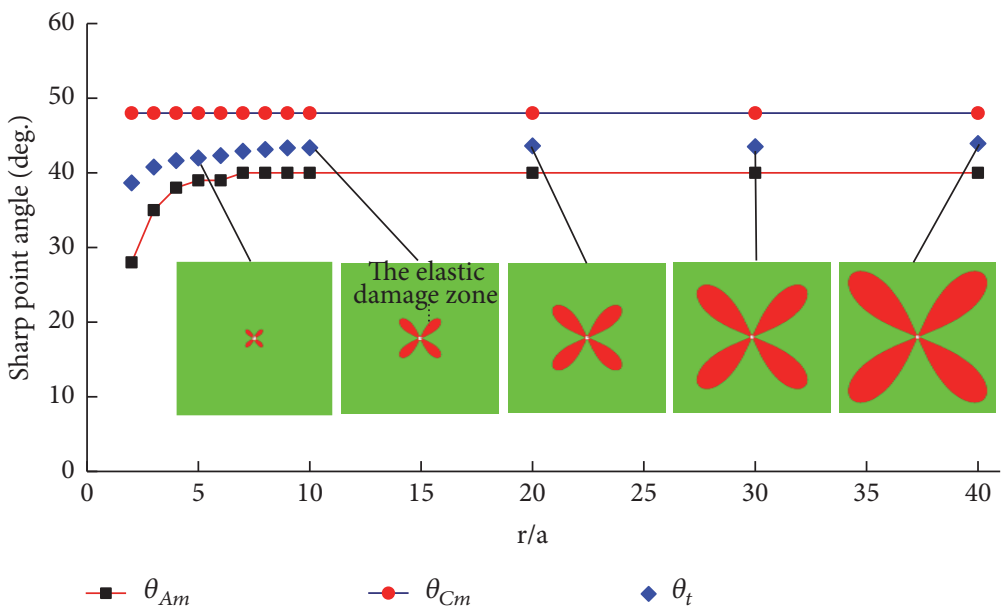

(c) Uniaxial compression

FIGURE 17: Diagram of the characteristic convergence of the elastic damage zone sharp point.

zone, the direction of the sharp-point plastic zone (expressed in $\theta_{v}$ ), and the distance from the sharp-point plastic zone to the cavity centre (expressed in $R$ ). The purpose of this simulation scheme is to verify the essence of the sharppoint failure, the directionality of the sharp point, and the rationality of the factors determined by the sharp-point angle criterion, and also to determine the mechanism of the rock properties in the sharp-point failure. The second scheme proceeds as follows: Keeping the lateral pressure coefficient and the rock parameters unchanged, we studied the impact of the vertical stress on the rock surrounding a sharp-point failure. The purpose of this simulation scheme is to verify 


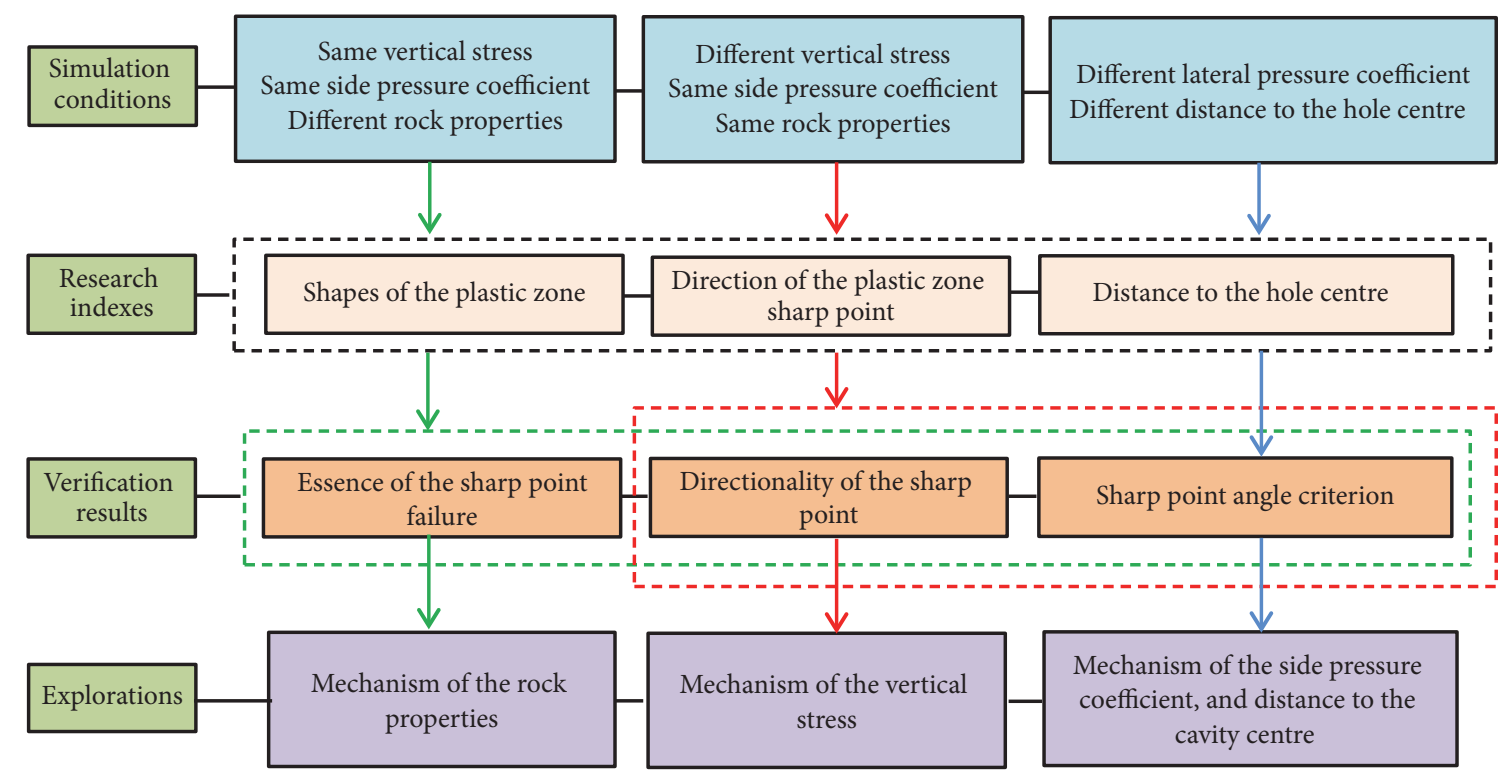

FIGURE 18: Numerical simulation methods.

the directionality of the sharp point and the rationality of the factors determined by the sharp-point angle criterion, and also to determine the mechanism of the vertical stress in the sharp-point failure. The third scheme proceeds as follows: On the basis of the verification of schemes of 1 and 2, we studied the expanding direction of the sharp point under the condition of different lateral pressure coefficients. The purpose of this simulation scheme is to verify the rationality of the factors determined by the sharp-point angle criterion and to determine the mechanism of the factors in the sharppoint failure.

In the FLAC ${ }^{3 \mathrm{D}}$ model, the length unit is considered to be equal to the circular cavity radius, and the sizes of the threedimensional (3D) model are as follows: $x: y: z=60: 10: 60$ (the direction of $y$ is the axial direction of the circular cavity). The failure of the rock surrounding an underground cavity is actually a $3 \mathrm{D}$ space problem. To make the theory solvable, we need to simplify it to a two-dimensional model. In the verification phase, the actual situation of the underground cavity was considered as much as possible and the $3 \mathrm{D}$ numerical models were used in this work.

5.1. Directional Sharp-Point Failure under Different Rock Material Properties. According to the results of existing literature [27-33], the sharp-point failure is easy to form around a circular cavity under a stress field $(\lambda=3, P=20 \mathrm{MPa})$. Keeping the stress field unchanged $(\lambda=3, P=20 \mathrm{MPa})$, we selected nine types of rock materials with different mechanical properties for the simulation, as shown in Table 1. The Mohr-Coulomb strength criterion was adopted in the simulation. The shear strength of the nine different rock materials increased gradually, and the common rock mechanics parameters were considered [28-31]. The results of the simulation are shown in Figure 19.
(1) Verification Analysis of the Essence of the Sharp-Point Failure. In Figure 19, the plastic zones of the rock surrounding a circular cavity show a similar distribution characteristic: the scope of the circumferential plastic zone decreases gradually with the distance away from the cavity centre, and, finally, it becomes a sharp point. This distribution characteristic of the plastic zone is completely consistent with the sharp-angular distribution law of the stress destructive power around a circular cavity in a nonuniform stress field. In the same stress field, nine different rock materials showed a similar sharppoint failure characteristic. Therefore, the directional sharppoint failure of rock surrounding a circular cavity is directly determined by the distribution characteristics of the stress field around the circular cavity, and rock with any material properties will suffer priority damage at the stress sharp point. Consequently, the present analysis of the mechanism of sharp-point failure of the rock surrounding a circular cavity is reasonable.

(2) Verification Analysis of the Sharp-Point Directionality. Under the simulated stress conditions, the nine different rock materials all showed a sharp-point failure zone around a cavity. In Figure 19(9), the range of the plastic zone was the smallest $(R / a=2.4)$, although there was an obvious sharp angle in the plastic zone. When the range of the plastic zone $R / a$ expanded from 2.4 to 20.2, the sharp-point angles of the plastic zone were all around $38.5^{\circ}$. After the sharp angle appeared in the plastic zone, the expansion direction of the sharp-point plastic zone hardly changed and the plastic zone expanded in one direction.

(3) Mechanism of the Rock Properties in the Sharp-Point Failure. In a certain stress field, the properties of the rock material will affect the extension range of the plastic zone, as shown in Figure 19. The range of the plastic zone decreases 
TABLE 1: Mechanical parameters of the materials used in the simulation.

\begin{tabular}{|c|c|c|c|c|c|c|}
\hline Number & $\begin{array}{c}\text { Compressive } \\
\text { strength/(MPa) }\end{array}$ & $\begin{array}{c}\text { Tensile strength } \\
\text { /(MPa) }\end{array}$ & $\begin{array}{c}\text { Elastic modulus } \\
/(\mathrm{GPa})\end{array}$ & Poisson's ratio & Cohesion/(MPa) & $\begin{array}{c}\text { Internal friction } \\
\text { angle/(deg) }\end{array}$ \\
\hline 1 & 12.80 & 0.35 & 6.0 & 0.21 & 4.0 & 26 \\
\hline 2 & 16.32 & 0.85 & 5.5 & 0.21 & 4.5 & 27 \\
\hline 3 & 19.97 & 1.35 & 5.0 & 0.21 & 5.0 & 28 \\
\hline 4 & 23.76 & 1.85 & 4.5 & 0.22 & 5.5 & 29 \\
\hline 5 & 27.71 & 2.35 & 4.0 & 0.22 & 6.0 & 30 \\
\hline 6 & 31.81 & 2.85 & 3.5 & 0.22 & 6.5 & 31 \\
\hline 7 & 36.08 & 3.35 & 3.0 & 0.23 & 7.0 & 32 \\
\hline 8 & 40.51 & 3.85 & 2.5 & 0.23 & 7.5 & 33 \\
\hline 9 & 45.14 & 4.35 & 2.0 & 0.23 & 8.0 & 34 \\
\hline
\end{tabular}

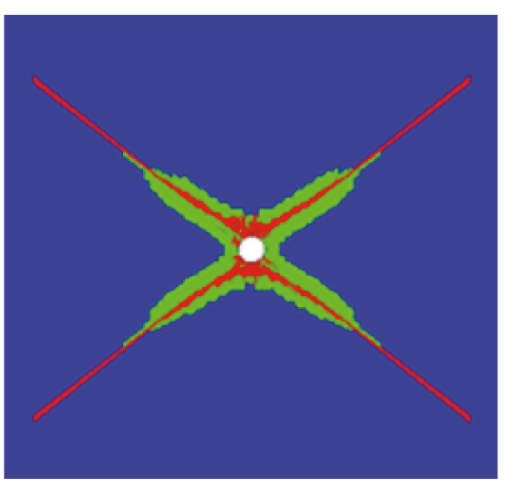

(1) $R / a=20.2, \theta_{p}=38.37^{\circ}$

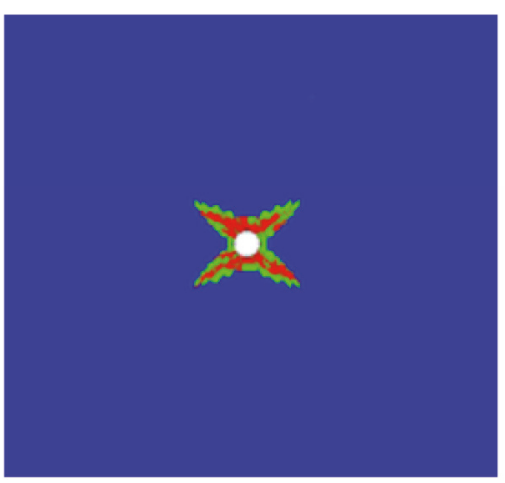

(4) $R / a=4.6, \theta_{p}=38.27^{\circ}$

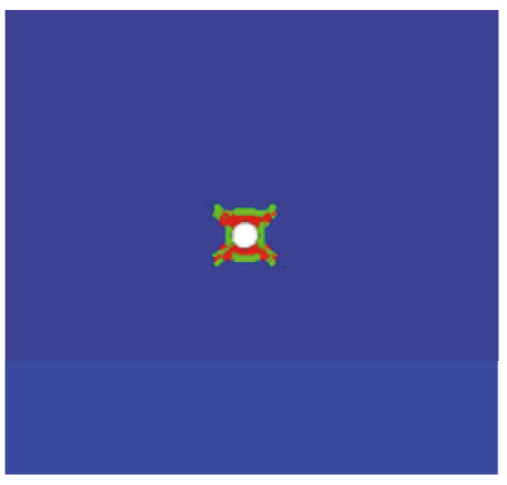

(7) $R / a=2.7, \theta_{p}=38.34^{\circ}$

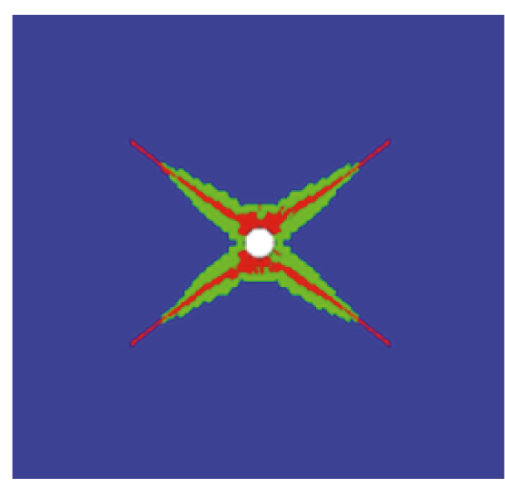

(2) $R / a=10.6, \theta_{p}=38.32^{\circ}$

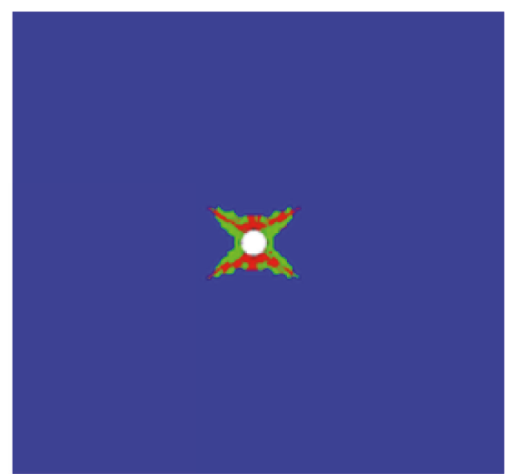

(5) $R / a=3.9, \theta_{p}=38.65^{\circ}$

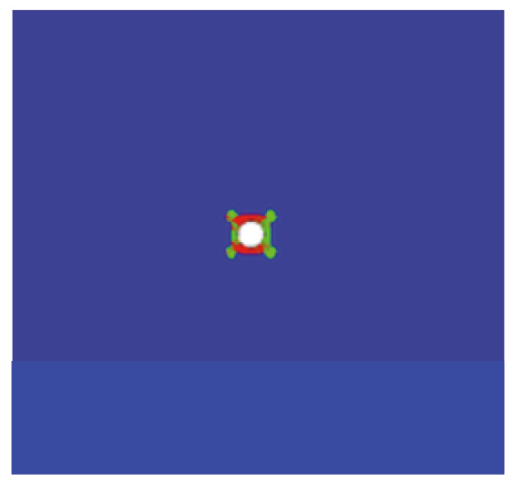

(8) $R / a=2.5, \theta_{p}=38.43^{\circ}$

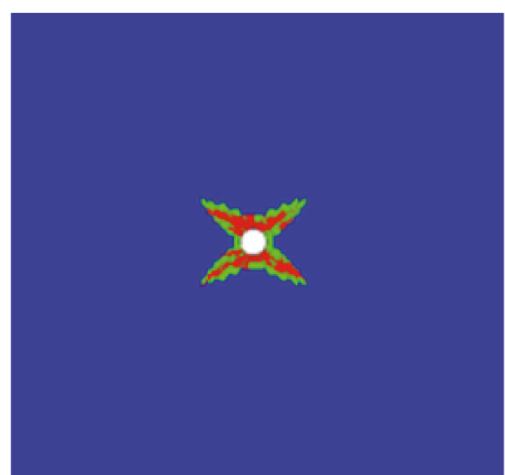

(3) $\mathrm{R} / \mathrm{a}=4.8, \theta_{p}=38.29^{\circ}$

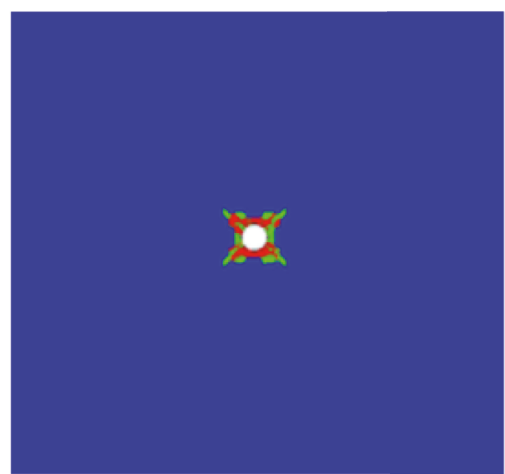

(6) $R / a=2.8, \theta_{p}=38.25^{\circ}$

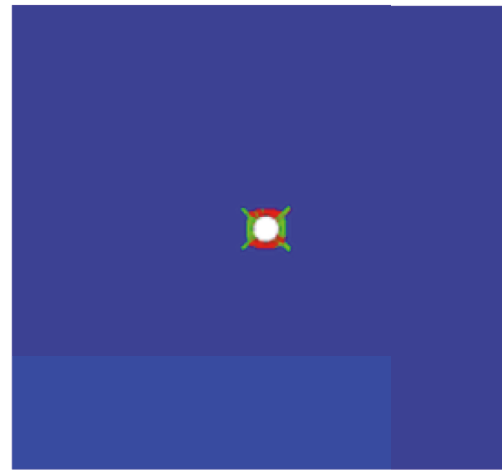

(9) $R / a=2.4, \theta_{p}=38.32^{\circ}$

FIGURE 19: Directional sharp-point failure under the condition of different rock material properties. 


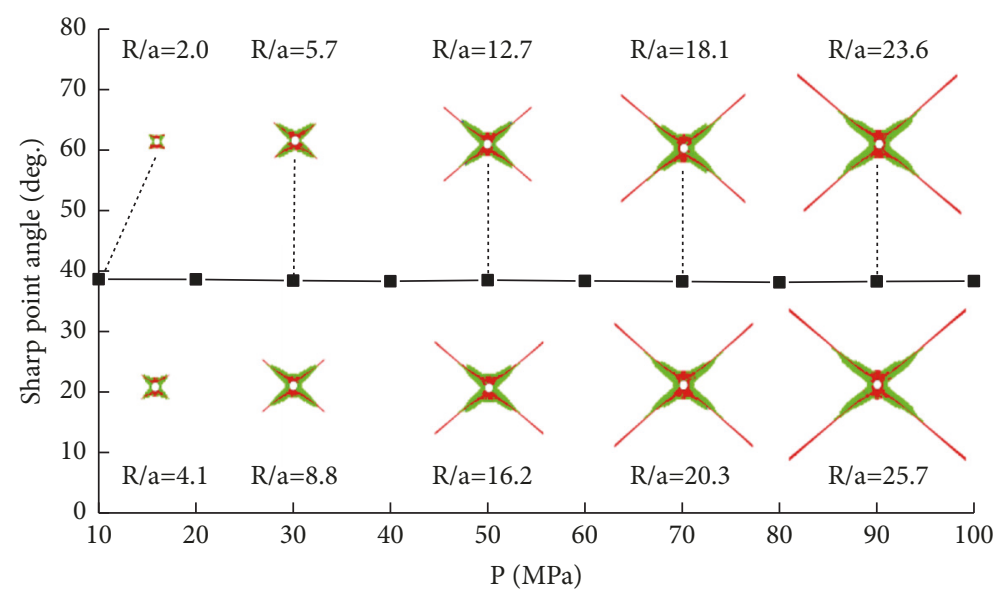

FIGURE 20: Directional sharp-point failure under the condition of different vertical stresses.

TABLE 2: Mechanical parameters of the materials used in the simulation.

\begin{tabular}{lccccc}
\hline $\begin{array}{l}\text { Compressive } \\
\text { strength } \\
/(\mathrm{MPa})\end{array}$ & $\begin{array}{c}\text { Tensile } \\
\text { strength } \\
/(\mathrm{MPa})\end{array}$ & $\begin{array}{c}\text { Elastic } \\
\text { modulus } \\
/(\mathrm{GPa})\end{array}$ & $\begin{array}{c}\text { Poisson's } \\
\text { ratio }\end{array}$ & $\begin{array}{c}\text { Cohesion } \\
/(\mathrm{MPa})\end{array}$ & $\begin{array}{c}\text { Internal } \\
\text { friction } \\
\text { angle } \\
/(\mathrm{deg})\end{array}$ \\
\hline 27.71 & 2.35 & 4.0 & 0.22 & 6.0 & 30 \\
\hline
\end{tabular}

gradually with the increase in rock strength. The failure characteristics of the surrounding rock are entirely determined by the distribution laws of the stress field around a circular cavity, and the distribution characteristics of the stress field are related to the distance to the cavity centre. Under a constant stress condition, the distribution of the stress field around a circular cavity was determined, and different rock materials showed the distribution characteristics of the stress field in different regions.

\subsection{Directional Sharp-Point Failure under Different Vertical} Stresses. With the lateral pressure coefficient and the rock parameters kept unchanged $(\lambda=3$; the rock parameters are shown in Table 2), the vertical stress gradually increased from $10 \mathrm{MPa}$ to $100 \mathrm{MPa}$. The shapes and the sharp-point angles of the plastic zone under different vertical stress conditions were studied statistically. The results of the simulation are shown in Figure 20.

(1) Verification Analysis of the Sharp-Point Directionality. With the vertical stress increasing from $10 \mathrm{MPa}$ to $100 \mathrm{MPa}$, the rock surrounding the plastic zone shows the same sharp angular distribution characteristic, as shown in Figure 20. The range of the plastic zone was the smallest $(R / a=2.0)$ when the vertical stress was the smallest $(P=10 \mathrm{MPa})$, although there was an obvious sharp angle in the plastic zone. When the range of the plastic zone R/a expanded from 2.0 to 25.7, the sharp-point angles of the plastic zone were all basically around $38.5^{\circ}$. After the sharp angle appeared in the plastic zone, the expansion direction of the sharp-point plastic zone hardly changed and the plastic zone expanded in one direction.

(2) Mechanism of the Vertical Stress in the Sharp-Point Failure. Under certain conditions of the rock material and the lateral pressure coefficient, the vertical stress will affect the extension range of the plastic zone, as shown in Figure 19. The range of the plastic zone increases gradually with the increase in vertical stress. Based on formula (2), the vertical stress $P$ is a common factor in the stress solutions, and the stress values of each point in the field will be magnified with an increase of $P$, but the sharp-angular distribution of the stress field around a circular cavity will not be changed. Consequently, the sharp-point angle in each circumferential position will not be changed with the change of $P$. According to formulas (17), (18), and (19), the stress sharp-point angle was determined by the lateral pressure coefficient and the distance to the cavity centre. The vertical stress will affect the extension range of the plastic zone, and, therefore, the different vertical stresses show the distribution characteristics of the stress sharp-point angle in different regions.

5.3. Directional Sharp-Point Failure under Different Lateral Pressure Coefficients. According to the verification analysis of schemes 1 and 2, the sharp-point failure of the rock surrounding a circular cavity is determined by the special distribution of the stress field around the cavity, and the position of the stress sharp point is directly related to the lateral pressure coefficient and the distance to the cavity centre. The rock properties and vertical stresses affect the position of the sharp-point failure zone by affecting the failure zone range in the stress field. In this part, the plastic zone range is changed by changing the vertical stress and the properties of the surrounding rock simultaneously, and the distribution of the angle of the sharp-point plastic zone under the plastic zone range from 2 to 40 with different lateral pressure coefficients (from 2 to 10 ) was simulated and studied. The results of the simulation are shown in Figure 21. 


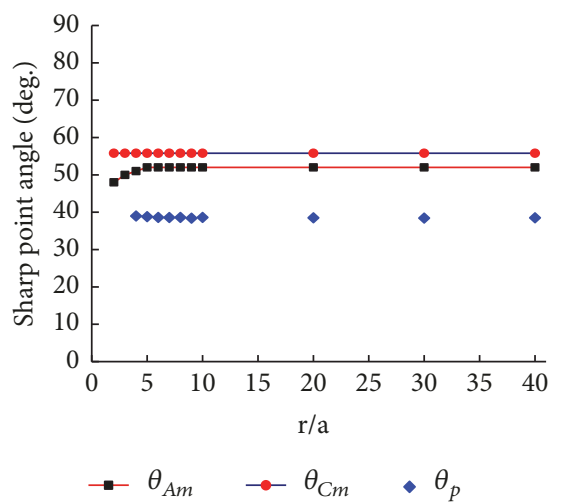

(1) $\lambda=2$

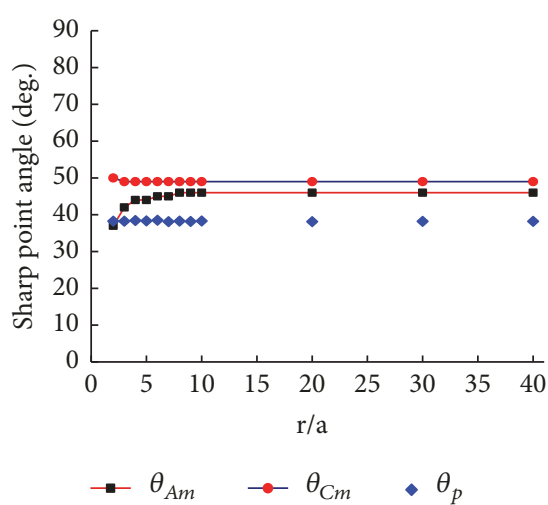

(4) $\lambda=5$

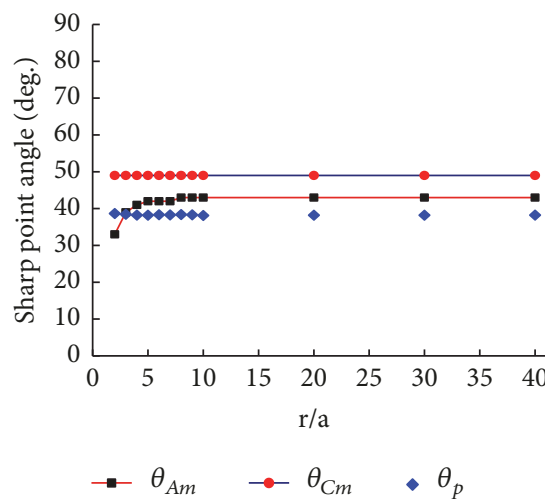

(7) $\lambda=8$

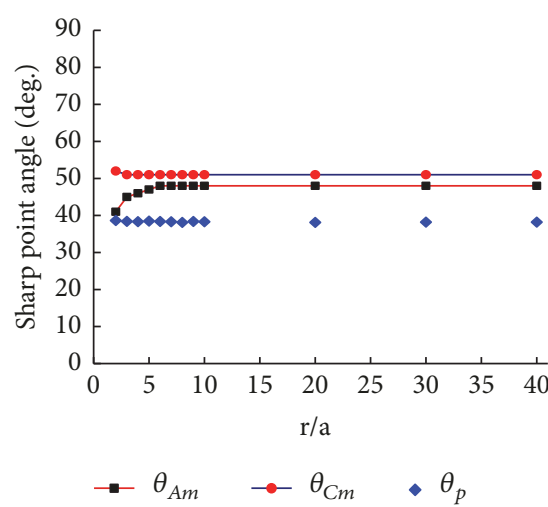

(2) $\lambda=3$

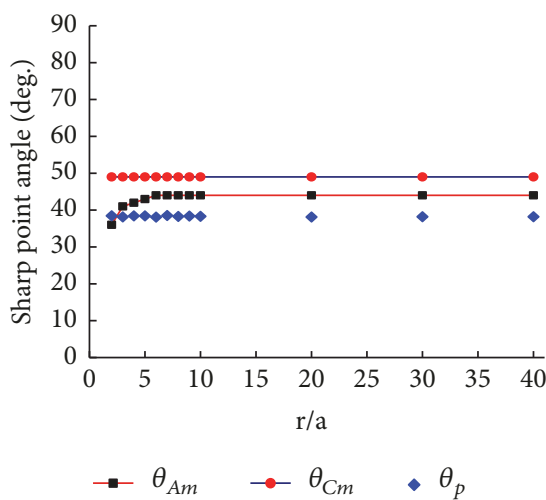

(5) $\lambda=6$

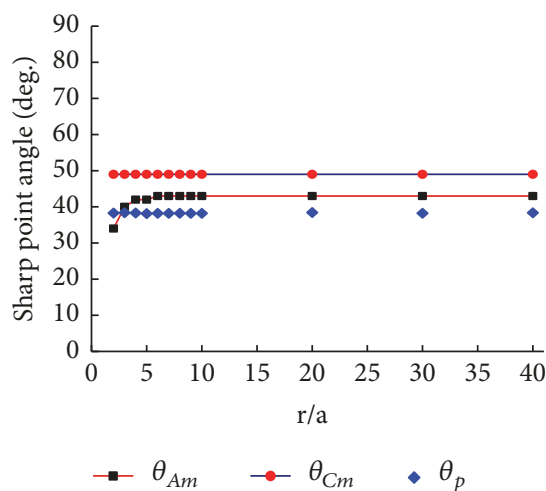

(8) $\lambda=9$

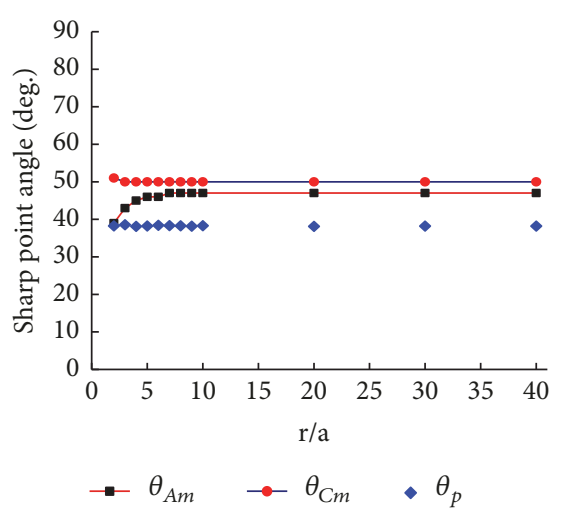

(3) $\lambda=4$

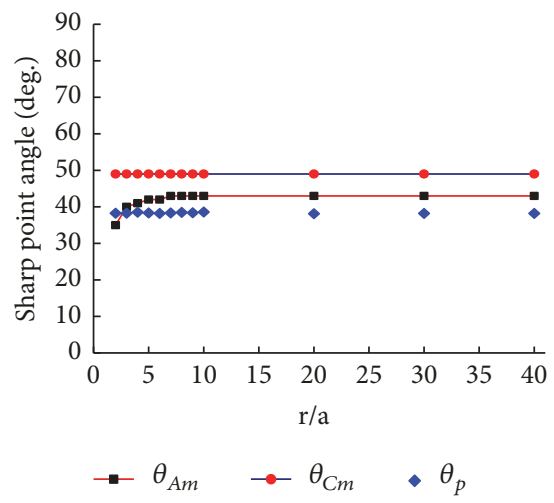

(6) $\lambda=7$

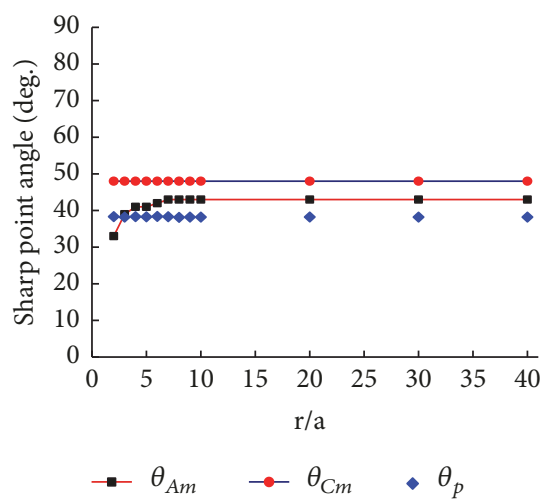

(9) $\lambda=10$

FIGURE 21: Comparison between the numerical simulation and the theoretical calculation of the sharp-point angle.

(1) Verification Analysis of the Sharp-Point Directionality. In Figure 21, under the different lateral pressure coefficients, there will be obvious sharp angles when the plastic zone extends to a certain range, and then it will continue to expand along the sharp angular direction. When the lateral pressure coefficient is 2 as shown in Figure 21(1), the outline of the plastic zone is a smooth elliptical shape $[36,37]$ when its range is less than four times the cavity radius $(R / a<4)$, and there is no obvious sharp angle on the plastic zone; obvious sharp angles will appear when the range of the plastic zone is more than four times the cavity radius $(R / a>4)$, in which case, it will continue to expand along the sharp-angular direction (approximately $38.5^{\circ}$ ). When the lateral pressure coefficient is more than 3, obvious sharp angles will appear when the range of the plastic zone is very small $(R / a=2)$, in which case, it will continue to expand along the sharp-angular direction (approximately $38.5^{\circ}$ ). Therefore, the sharp angle will appear when the plastic zone extends to a larger range under the condition of a small lateral pressure coefficient or when the plastic zone extends to a small range under the condition of a larger lateral pressure coefficient, and then the plastic zone will continue to expand along the sharp-angular direction (approximately $38.5^{\circ}$ ).

(2) Analysis of the Error between the Plastic Zone and the Stress Sharp-Point Angles. The stress solution around a circular cavity in formula (2) was based on the elastic mechanics. The purpose of this study was to evaluate the rock surrounding a 
failure zone with the help of the distribution law of the elastic stress field; the effect of the failure zone on the stress field was not considered, however. Therefore, there must be some deviations between the plastic zone and the stress sharppoint angle calculated by numerical simulation and theory. According to the numerical simulation results, the difference between the plastic zone and the stress sharp-point angles was large under the condition of a small lateral pressure coefficient, reaching $10^{\circ}$, whereas it gradually decreased and could be controlled within $5^{\circ}$ with the increase in the lateral pressure coefficient. The directional sharp-point failure of the surrounding rock is consistent with the angular distribution of the stress field, and there was a certain deviation in the numerical value between the sharp angles but within the controllable range.

(3) Mechanism of the Lateral Pressure Coefficient in the SharpPoint Failure. As shown in Figures 8, 10, and 12, the lateral pressure coefficient has two effects on the stress field. First, when the lateral pressure coefficient increases, the stresses at the circumferential position around a circular cavity will increase as a whole, the stress destructive power of each point will increase, and the damage scope of the surrounding rock will also increase. Second, as shown in Figures 10 and 12, the greater the lateral pressure coefficient, the steeper the stress curves and the more obvious the sharp-angular distribution of the stress field, and the sharp angle of the failure zone will appear in the smaller failure zone range.

(4) Directional Sharp-Point Failure under Uniaxial Compression. To prove the universality of the directional sharp-point failure rules of the surrounding rock, we studied the stress field around a circular cavity under uniaxial compression, as shown in Figure 17(c). The lateral pressure coefficient tends to infinity under uniaxial compression, and the general applicability of the directional sharp-point failure rules can be verified by compared with the situations of the lateral pressure coefficient from 2 to 10 . Under uniaxial compression, an obvious sharp angle will appear when the range of the plastic zone is very small $(R / a=2)$, and then it will continue to expand along the sharp-angular direction (approximately $38.5^{\circ}$ ), as shown in Figure 22. It is exactly the same as the situations of the lateral pressure coefficient from 3 to 10 . The difference between the plastic zone and the stress sharp-point angles reaches the minimum value of $2.5^{\circ}$ under uniaxial compression. The directional sharp-point failure of the rock surrounding a circular cavity in a nonuniform stress field is a universal law: there will be obvious sharp angles when the plastic zone extends to a certain range, and then it will continue to expand along the sharp-angular direction. When the lateral pressure coefficient is less than 2, obvious sharp angles will appear when the range of the plastic zone is more than four times the cavity radius $(R / a>4)$, and then it will continue to expand along the sharp-angular direction (approximately $38.5^{\circ}$ ). When the lateral pressure coefficient is more than 3, obvious sharp angles will appear when the range of the plastic zone is very small $(R / a=2)$, and then it will continue to expand along the sharp-angular direction (approximately $38.5^{\circ}$ ).

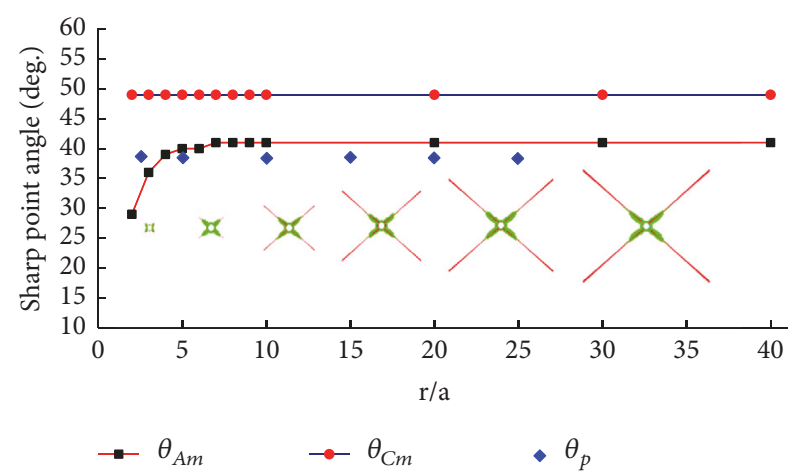

Figure 22: Comparison between the numerical simulation and the theoretical calculation of the sharp-point angle under uniaxial compression.

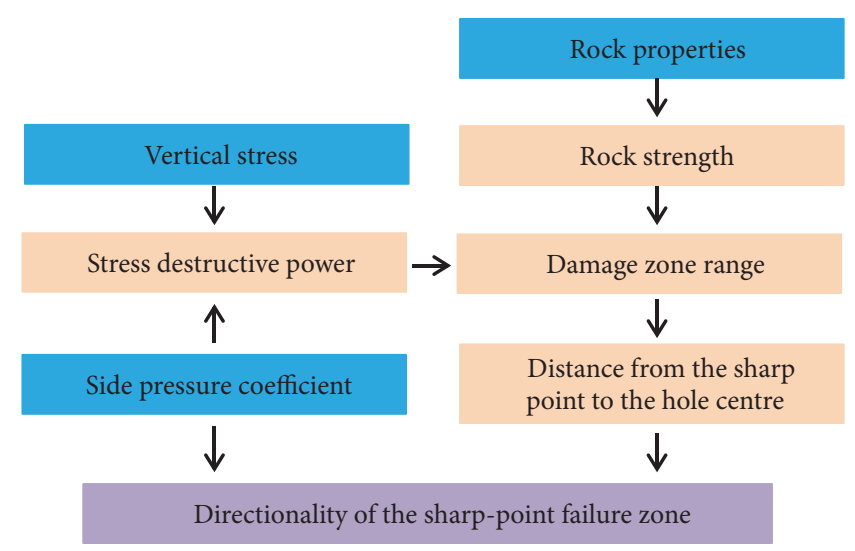

FIGURE 23: Relationship between the factors in the sharp-point angle criterion.

5.4. Interaction Mechanism of the Factors on the Directionality of the Sharp-Point Failure Zone. The laws of the directional sharp-point failure of the rock surrounding a circular cavity were discussed. Based on the Mohr-Coulomb strength criterion, the factors affecting rock failure include stress conditions (vertical stress and lateral pressure coefficient) and rock mechanical properties. The lateral pressure coefficient and the distance to the cavity centre $(R / a)$ directly affect the distribution of the stress sharp-point angle around a circular cavity. Therefore, they are the direct effective factors. Both rock properties and vertical stress indirectly affect the direction of the sharp-point failure zone by affecting the extension range of the plastic zone. The lateral pressure coefficient and the vertical stress simultaneously control the stress destructive power, and the rock properties determine the shear strength of the rock material. The interaction between the stress destructive power and the rock shear strength determines the extension range of the plastic zone and ultimately affects the direction of the sharp-point failure zone. The interaction mechanism of the factors on the directionality of the sharp-point failure zone is shown in Figure 23. 


\section{Conclusions}

To understand the failure mechanism and expansion rule of the rock surrounding an underground cavity, we studied the distribution characteristics of the circular stress field around an underground circular cavity and we presented the directional sharp-point failure mechanism of the rock surrounding such cavity. The main conclusions are as follows:

(1) The failure modes and expansion laws of the surrounding rock under large-scale failure were determined. An obvious sharp angle will be formed when the failure zone extends to a certain range, and then it will continue to expand along the sharp-angular direction.

(2) The mechanism of the sharp-point failure of the rock surrounding a circular cavity was determined. Along the circumferential direction, the stress destructive power around the circular cavity increases first and then decreases, showing a sharp-angular distribution, and the rock with any material properties will suffer priority damage at the stress sharp point, forming the sharp-point failure zone.

(3) The directional expansion mechanism of the sharppoint failure zone around a circular cavity was determined, and the stress sharp-point angle criterion was proposed. Under certain stress conditions, the stress sharp-point angle will tend to be stable when the distance to the cavity centre is more than a certain distance, and the directional distribution of the stress sharp-point angle is the mechanical essence of the directional expansion of the rock surrounding a failure zone.

(4) The directional sharp-point failure mechanism of the rock surrounding a circular cavity was verified by using the FLAC $^{3 \mathrm{D}}$ numerical simulation tests. The directional sharppoint failure of the rock surrounding a circular cavity in a nonuniform stress field is a universal law. When the lateral pressure coefficient is less than 2, obvious sharp angles will appear when the range of the plastic zone is more than four times the cavity radius $(R / a>4)$, and then it will continue to expand along the sharp-angular direction (approximately $38.5^{\circ}$ ). When the lateral pressure coefficient is more than 3 , obvious sharp angles will appear when the range of the plastic zone is very small $(R / a=2)$, and then it will continue to expand along the sharp-angular direction (approximately $38.5^{\circ}$ ).

(5) The large-scale expansion of the rock surrounding a failure area would cause severe destruction of the underground space and trigger underground disasters. According to the results of this work, the location of serious damage around a tunnel may be found. These results may provide references for the study of the underground engineering space maintenance, geological hazard prevention, and the failure mechanism of rock materials with cavities.

\section{Data Availability}

The data used to support the findings of this study are available from the corresponding author upon request.

\section{Conflicts of Interest}

The authors declare no conflicts of interest.

\section{Acknowledgments}

The authors wish to sincerely thank various organizations for their financial support. This work was partially supported by the National Natural Science Foundation of China (51704294, 51234006) and the National Key Research and Development Program (2016YFC0600708).

\section{References}

[1] J. R. Vidal-Romaní, L. González-López, M. Vaqueiro, and J. Sanjurjo-Sánchez, "Bioweathering related to groundwater circulation in cavities of magmatic rock massifs," Environmental Earth Sciences, vol. 73, no. 6, pp. 2997-3010, 2015.

[2] J. Castro, K. Cashman, N. Joslin, and B. Olmsted, "Structural origin of large gas cavities in the Big Obsidian Flow, Newberry volcano," Journal of Volcanology and Geothermal Research, vol. 114, no. 3-4, pp. 313-330, 2002.

[3] F. Gutiérrez, M. Parise, J. De Waele, and H. Jourde, "A review on natural and human-induced geohazards and impacts in karst," Earth-Science Reviews, vol. 138, pp. 61-88, 2014.

[4] G. F. Andriani and M. Parise, "On the applicability of geomechanical models for carbonate rock masses interested by karst processes," Environmental Earth Sciences, vol. 74, no. 12, pp. 7813-7821, 2015.

[5] R. W. Howarth, A. Ingraffea, and T. Engelder, "Natural gas: should fracking stop?” Nature, vol. 477, no. 7364, pp. 271-273, 2011.

[6] J. Kriesky, B. D. Goldstein, K. Zell, and S. Beach, "Differing opinions about natural gas drilling in two adjacent counties with different levels of drilling activity," Energy Policy, vol. 58, pp. 228-236, 2013.

[7] J. G. S. N. Visser, "The development of underground freight transport: an overview," Tunnelling and Underground Space Technology, vol. 80, pp. 123-127, 2018.

[8] L. Jiang, P. Kong, J. Shu, and K. Fan, "Numerical analysis of support designs based on a case study of a longwall entry," in Rock Mechanics and Rock Engineering, pp. 1-12, 2019.

[9] X. L. Yang and F. Huang, "Three-dimensional failure mechanism of a rectangular cavity in a Hoek-Brown rock medium," International Journal of Rock Mechanics and Mining Sciences, vol. 61, pp. 189-195, 2013.

[10] F. D. E. Latief, U. Fauzi, S. Bijaksana, and Y. Bindar, "Pore structure characterization of $3 \mathrm{D}$ random pigeon hole rock models," International Journal of Rock Mechanics and Mining Sciences, vol. 47, no. 3, pp. 523-531, 2010.

[11] J.-P. Liu, Y.-H. Li, and S.-D. Xu, "Estimation of cracking and damage mechanisms of rock specimens with precut holes by moment tensor analysis of acoustic emission," International Journal of Fracture, vol. 188, no. 1, pp. 1-8, 2014.

[12] Z. Zhang, C.-A. Tang, Q.-L. Yu, and D. Duan, "Numerical simulation on influence coefficient of lateral pressure on broken zone of circular aperture," Yantu Lixue/Rock and Soil Mechanics, vol. 30, no. 2, pp. 413-418, 2009.

[13] M. Prudencio and M. van Sint Jan, "Strength and failure modes of rock mass models with non-persistent joints," International Journal of Rock Mechanics and Mining Sciences, vol. 44, no. 6, pp. 890-902, 2007.

[14] L. N. Y. Wong and H. H. Einstein, "Crack coalescence in molded gypsum and Carrara marble. Part 1. Macroscopic observations and interpretation," Rock Mechanics and Rock Engineering, vol. 42, no. 3, pp. 475-511, 2009. 
[15] L. N. Y. Wong and H. H. Einstein, "Crack coalescence in molded gypsum and Carrara marble: part 2-microscopic observations and interpretation," Rock Mechanics and Rock Engineering, vol. 42, no. 3, pp. 513-545, 2009.

[16] G. M. Fonseka, S. A. F. Murrelli, and P. Barnesj, "Scanning electron microscope and emission studies of crack development in rocks," International Journal of Rock Mechanics and Mining Sciences \& Geomechanics Abstracts, vol. 22, pp. 273-289, 1985.

[17] S.-H. Chang and C.-I. Lee, "Estimation of cracking and damage mechanisms in rock under triaxial compression by moment tensor analysis of acoustic emission," International Journal of Rock Mechanics and Mining Sciences, vol. 41, no. 7, pp. 10691086, 2004.

[18] R. H. C. Wonga, K. T. Chaua, C. A. Tangb, and P. Lin, "Analysis of crack coalescence in rock-like materials containing three flaws-Part I: experimental approach," International Journal of Rock Mechanics \& Mining Sciences, vol. 38, pp. 909-924, 2001.

[19] C. A. Tang, P. Lin, R. H. C. Wong, and K. T. Chau, "Analysis of crack coalescence in rock-like materials containing three flaws-Part II: numerical approach," International Journal of Rock Mechanics and Mining Sciences, vol. 38, no. 7, pp. 925-939, 2001.

[20] S.-Q. Yang, X.-R. Liu, and H.-W. Jing, "Experimental investigation on fracture coalescence behavior of red sandstone containing two unparallel fissures under uniaxial compression," International Journal of Rock Mechanics and Mining Sciences, vol. 63, pp. 82-92, 2013.

[21] T. Liu, B. Lin, Q. Zou, C. Zhu, and F. Yan, "Mechanical behaviors and failure processes of precracked specimens under uniaxial compression: a perspective from microscopic displacement patterns," Tectonophysics, vol. 672-673, pp. 104-120, 2016.

[22] T. Liu, B. Lin, and W. Yang, "Mechanical behavior and failure mechanism of pre-cracked specimen under uniaxial compression," Tectonophysics, vol. 712-713, pp. 330-343, 2017.

[23] L. Xie, W. Zhu, S. Wang, and L. Niu, “Three-Dimensional parallel computing on failure process of rock specimen with a pre-existing circular opening," Chinese Journal of Geotechnical Engineering, vol. 33, pp. 1147-1156, 2011.

[24] S. Y. Wang, S. W. Sloan, and C. A. Tang, "Three-dimensional numerical investigations of the failure mechanism of a rock disc with a central or eccentric hole," Rock Mechanics and Rock Engineering, vol. 47, no. 6, pp. 2117-2137, 2014.

[25] Z. Zhao, N. Ma, X. Guo, X. Zhao, and L. Fan, "Falling principle and support design of butterfly-failure roof in large deformation mining roadways," Journal of China Coal Society, vol. 41, pp. 2932-2939, 2016.

[26] B. Shen, A. King, and H. Guo, "Displacement, stress and seismicity in roadway roofs during mining-induced failure," International Journal of Rock Mechanics and Mining Sciences, vol. 45, no. 5, pp. 672-688, 2008.

[27] Q. Chang, H. Zhou, Z. Xie, and S. Shen, "Anchoring mechanism and application of hydraulic expansion bolts used in soft rock roadway floor heave control," International Journal of Mining Science and Technology, vol. 23, no. 3, pp. 323-328, 2013.

[28] J.-C. Wang, "Mechanism of the rib spalling and the controlling in the very soft coal seam," Meitan Xuebao/Journal of the China Coal Society, vol. 32, no. 8, pp. 785-788, 2007.

[29] A. Mottahedi, F. Sereshki, and M. Ataei, "Overbreak prediction in underground excavations using hybrid ANFIS-PSO model," Tunnelling and Underground Space Technology, vol. 80, pp. 1-9, 2018.
[30] N. Ma, X. Zhao, Z. Zhao, X. Guo, H. Liu, and H. Jia, "Conjecture about mechanism of butterfly-shape coal and gas outburst in excavation roadway," Journal of Mining Science and Technology, vol. 2, pp. 137-149, 2017.

[31] N.-J. Ma, X.-F. Guo, Z.-Q. Zhao, X.-D. Zhao, and H.-T. Liu, "Occurrence mechanisms and judging criterion on circular tunnel butterfly rock burst in homogeneous medium," Meitan Xuebao/Journal of the China Coal Society, vol. 41, no. 11, pp. 2679-2688, 2016.

[32] Z. Zhao, N. Ma, X. Guo, X. Zhao, Y. Xia, and Z. Ma, "Mechanism conjecture of butterfly rock burst in coal seam roadway," Journal of China Coal Society, vol. 41, pp. 2689-2697, 2016.

[33] N. Ma, J. Li, X. Zhao, Z. Zhao, H. Liu, and H. Jia, "High quality gas channel and its construction method applied to coal and gas simultaneous extraction in deep mining," Journal of China Coal Society, vol. 40, pp. 742-748, 2015.

[34] X. Guo, N. Ma, X. Zhao, Z. Zhao, and Y. Li, "General shapes and criterion for surrounding rock mass plastic zone of round roadway," Journal of China Coal Society, vol. 41, pp. 1871-1877, 2016.

[35] H.-S. Jia, N.-J. Ma, and Q.-K. Zhu, "Mechanism and control method of roof fall resulted from butterfly plastic zone penetration," Meitan Xuebao/Journal of the China Coal Society, vol. 41, no. 6, pp. 1384-1392, 2016.

[36] M. Tao, H. Zhao, X. Li, X. Li, and K. Du, "Failure characteristics and stress distribution of pre-stressed rock specimen with circular cavity subjected to dynamic loading," Tunnelling and Underground Space Technology, vol. 81, pp. 1-15, 2018.

[37] M. Tao, A. Ma, W. Cao, X. Li, and F. Gong, "Dynamic response of pre-stressed rock with a circular cavity subject to transient loading," International Journal of Rock Mechanics and Mining Sciences, vol. 99, pp. 1-8, 2017.

[38] S. Wang, D. Li, C. Li, C. Zhang, and Y. Zhang, "Thermal radiation characteristics of stress evolution of a circular tunnel excavation under different confining pressures," Tunnelling and Underground Space Technology, vol. 78, pp. 76-83, 2018.

[39] H. G. Poulos and E. H. Davis, Elastic Solutions for Soil and Rock Mechanics, John Wiley, New York, NY, USA, 1974.

[40] M. Qian, P. Shi, and J. Xu, Mining Pressure and Strata Control, China University of Mining and Technology Press, Xuzhou, China, 2010.

[41] O. Heidbach, M. Tingay, A. Barth, J. Reinecker, D. Kurfeß, and B. Müller, "Global crustal stress pattern based on the World Stress Map database release 2008," Tectonophysics, vol. 482, no. 1-4, pp. 3-15, 2010.

[42] E. Hoek and E. T. Brown, Underground Excavations in Rock, Institution of Mining and Metallurgy, London, UK, 1980.

[43] C. Kirsch, "Die theorie der elastizitat und die bedurfnisse der festigkeitslehre," Zentralblatt Verein Deutscher Ingenieure, vol. 42, pp. 797-807, 1989.

[44] A. E. Green, The Elastic Equilibrium of Isotropic Plates and Cylinders, Proceedings of the Royal Society of London, London, UK, 1949. 


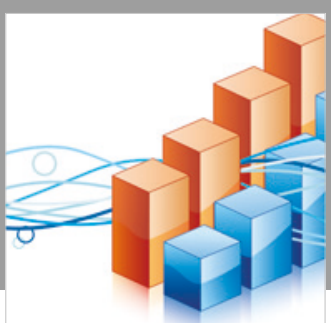

Advances in

Operations Research

\section{-n-m}
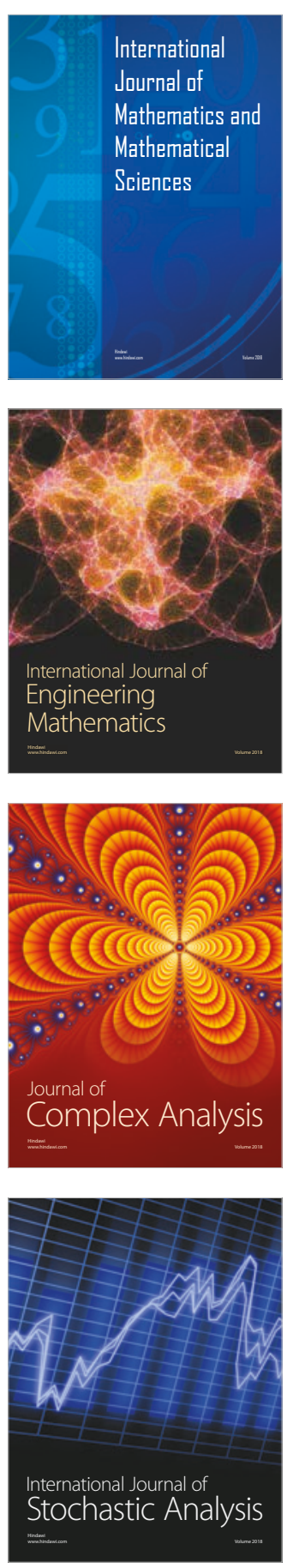
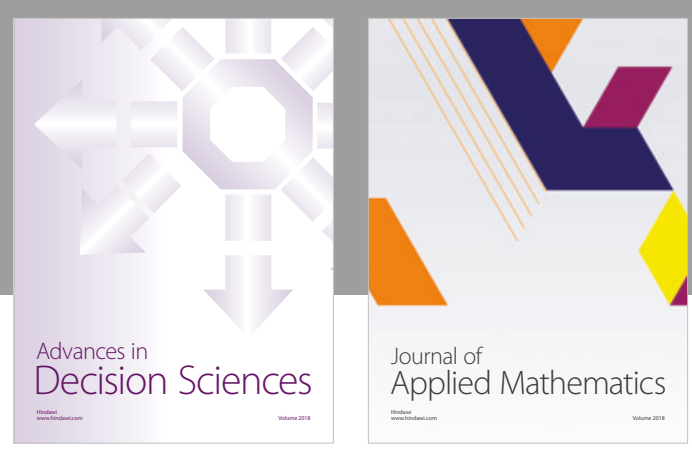

Journal of

Applied Mathematics
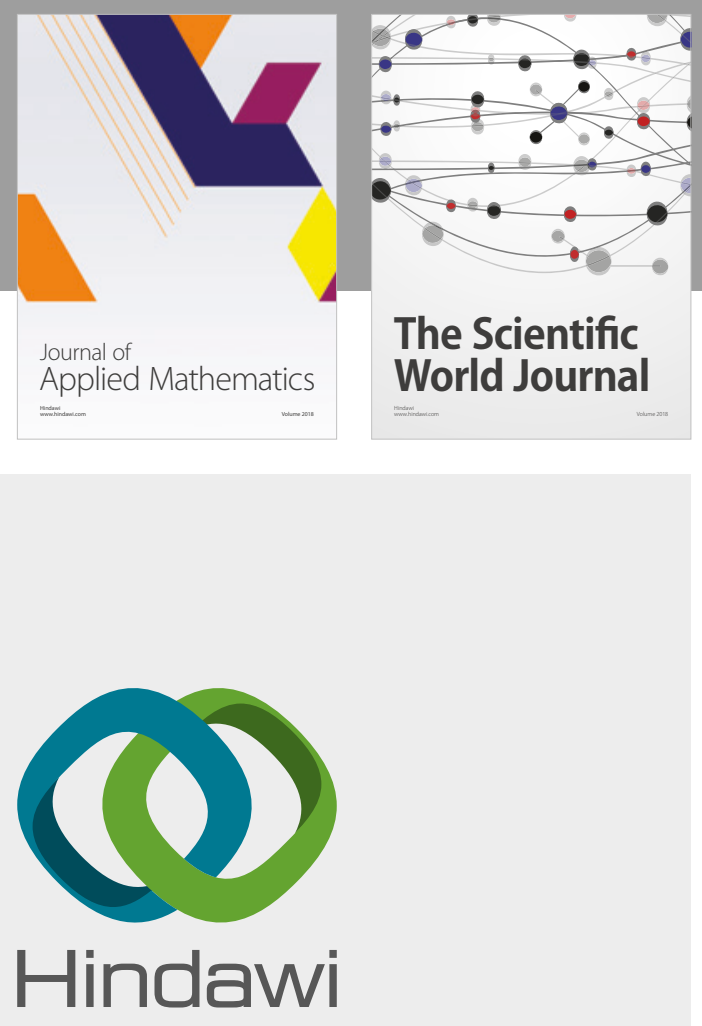

Submit your manuscripts at

www.hindawi.com

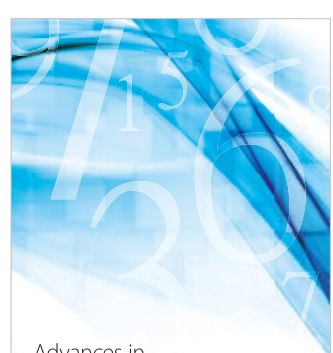

Advances in
Numerical Analysis
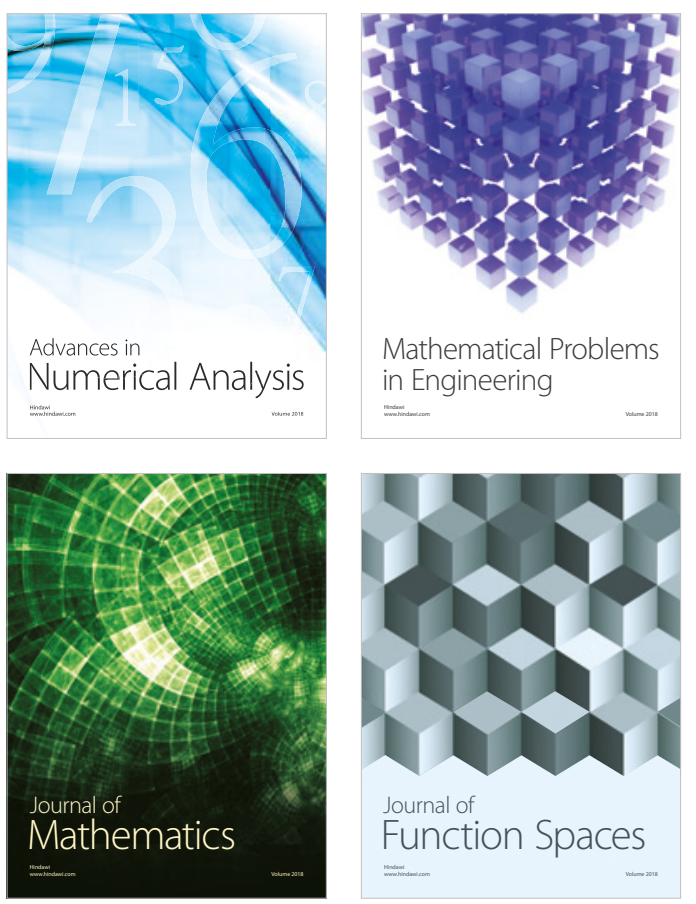

Mathematical Problems in Engineering

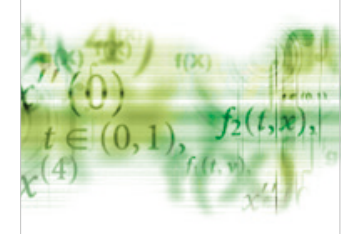

International Journal of

Differential Equations

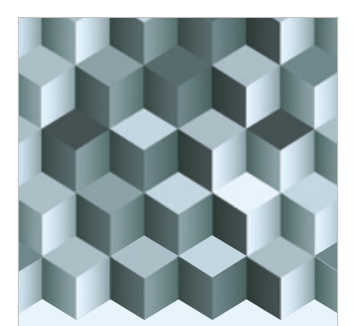

Journal of

Function Spaces

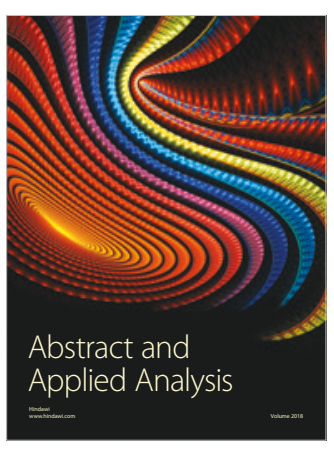

The Scientific

World Journal

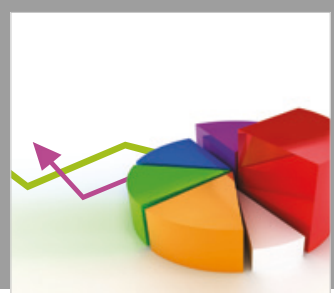

Journal of

Probability and Statistics
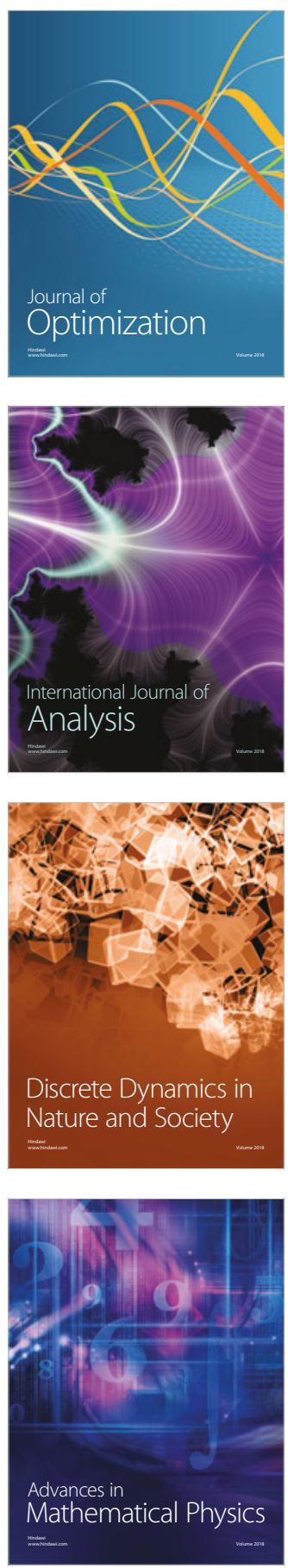